TAO, Vol. 15, No. 5, 785-811, December 2004

\title{
Factors Regulating the Distribution of Elements in the Sediments of a Seasonally Anoxic Lake in Tropical Taiwan
}

\author{
Chen-Tung Arthur Chen ${ }^{1, *}$ and Jen-Kang Wann ${ }^{2}$
}

(Manuscript received 25 June 2003, in final form 24 December 2003)

\begin{abstract}
Sixteen metals, both total and acid-leached, and their binding formations were quantified for the sediment column of the seasonally anoxic Great Ghost Lake. Since marked variation in the content of organic matter plays a major role in regulating the distribution of metals in sediments, this study provided insight into the relationship between organic matter and metals in a naturally anoxic water environment. Metals, $\mathrm{Al}, \mathrm{Cs}, \mathrm{Mg}, \mathrm{Rb}$ and $\mathrm{V}$, had significant negative correlations with total carbon content (TC) and occurred less often in mobile fractions. These findings indicate that these metals came from lithogenic sources and did not change much during early diagenesis. As a result, signals of these elements, whose origins can be traced back to long-range transport dust, were better preserved. Acid-leached contents of $\mathrm{Cs}, \mathrm{Mg}$ and $\mathrm{Rb}$ also had negative correlations with $\mathrm{TC}$, while both total and acid-leached As and $\mathrm{Cd}$ had good positive correlations with TC. Large portions of both As and Cd, were observed in mobile fractions (especially As) and came from organic sources and/or were incorporated into organic matter during early diagenesis (especially $\mathrm{Cd} d$ ). Long-term variations in redox conditions of the lake were induced by climate changes and might have influenced distributions of $\mathrm{Sr}$ and redox-sensitive $\mathrm{Mn}$ and $\mathrm{V}$ in mobile fractions. In addition to natural processes, enrichment of $\mathrm{Pb}$ and Cd near the core top was from anthropogenic aeolian sources. Finally, recent aeolian fluxes of $\mathrm{Al}$, As, Ba, Br, Ca, Cd, Ce, Cl, Cr, Cs, Cu, Er, Eu, Fe, Ga, Gd, K, La, Lu, Mg, Mn, Na, Nd, Ni, Pb, Rb, Si, Sm, Sr, Ti, Tm, V, Yb, $\mathrm{Zn}$ and $\mathrm{Zr}$ were estimated and large amounts of micronutrient $\mathrm{Fe}$ $\left(\sim 60 \mu \mathrm{g} \mathrm{cm}^{-2} \mathrm{yr}^{-1}\right)$, of aeolian origin, was also noted.
\end{abstract}

\footnotetext{
${ }^{1}$ Institute of Marine Geology and Chemistry, National Sun Yat-Sen University, Kaofsiung,Taiwan, ROC

2 General Education Center, Wenzao Ursuline College of Languages, Kaohsiung, Taiwan, ROC

* Corresponding author address: Prof. Chen-Tung Arthur Chen, Institute of Marine Geology and Chemistry, National Sun Yat-Sen University, Kaohsiung, Taiwan, ROC;

E-mail: ctchen@mail.nsysu.edu.tw
} 


\section{(Key words: Anoxic, Lake, Metals, Dust, Flux, Early diagenesis)}

\section{INTRODUCTION}

The variable water chemistry in lakes favors the study of geochemistry of an aquatic environment. The Great Ghost Lake (GGL) is seasonally stratified and anoxic (Chen and Wang 1990; Wang and Chen 1990). Undisturbed sediments of the lake serve as an archive of dust fallout. Chen et al. (1993) found that the high mountain lake contained coarse, organic carbonrich sediments with periodic appearances of a fine, organic carbon-poor layer. These dark and coarse-grained sediments were characterized by a single mode of $80 \mu \mathrm{m}$ or larger, and were formed in the watershed. The fine, bright sediments, however, were characterized by a single mode of $10 \mu \mathrm{m}$ or smaller and were of aeolian origin. Since dust storms from China have been found to affect Taiwan (Liu and Lin 2004; Chiang et al. 2004; Yuan et al. 2004; Chou et al. 2004; Lee and Liu 2004; Lin et al. 2004), the occurrence of gray colored sediments and bimodal particle size distribution (Fig. 1) suggest that dust storms were more frequent in China at about 1350AD (Chen et al. 2001).

The hypolimnion lake is anoxic most of the year but not during the winter turnover (Wann et al. 1997). The anoxic conditions promote anaerobic mineralization processes in anoxic bottom waters and underlying sediments (Stumm and Morgan 1981; Kuivila and Murray 1984; Sigg et al. 1991; Balistrieri et al. 1992a; Balistrieri et al. 1992b; Hamiltontaylor et al. 1996) and affect distributions of metals in sediments (Carignan and Nriagu 1985; Wann and Chen 1996; Schaller et al. 1997; Wann et al. 1997). During winter turnover, dissolved oxygen enters the anoxic hypolimnion and oxidizes the dissolved reduced species, especially redox-sensitive $\mathrm{Fe}$ and $\mathrm{Mn}$. Fe and Mn oxides are both good scavengers in the water column and able to remove other dissolved species (Balistrieri et al. 1992b; Hamiltontaylor et al. 1996; Xue et al. 1997; Wann et al. 1997). Elements removed by $\mathrm{Fe}$ and Mn oxides are released from sediment, when reductive dissolution of oxides occurs during stagnation (Davison et al. 1982; Davison and Woof 1984; Davison 1985; Balistrieri et al. 1992a; Balistrieri et al. 1992b).

Since climatic changes can affect the state of lake stagnation, these changes might play a significant, albeit indirect, role in regulating distributions of redox-sensitive elements in sediments of an anoxic lake. Previous studies on sediments of GGL by Chen et al. (1993), Lou et al. (1997) and Chen et al. (2001) examined their relationships with climatic changes, whereas Wann et al. (1995) and Wann and Chen (1996) only examined surface sediments and Wann et al. (1997), the Fe cycle. This study examined characteristics of the same lake but focused on factors regulating the distribution of elements in the sediment column based on core samples, which had not previously been the subject of a systematic study.

Transformation and re-mobilization of metals during early diagenesis are the major processes regulating the distribution of metals in anoxic sediments. These processes were evaluated to assess the contribution of aeolian metal fluxes. Transformation and mobility of metals depend on their specific chemical forms or binding formation in sediments. Therefore sequential extraction procedures were used to determine the forms of binding (Tessier et al. 1979; Salomons and Forstner 1980; Quevauviller et al. 1997) A 3-step sequential extraction proce- 


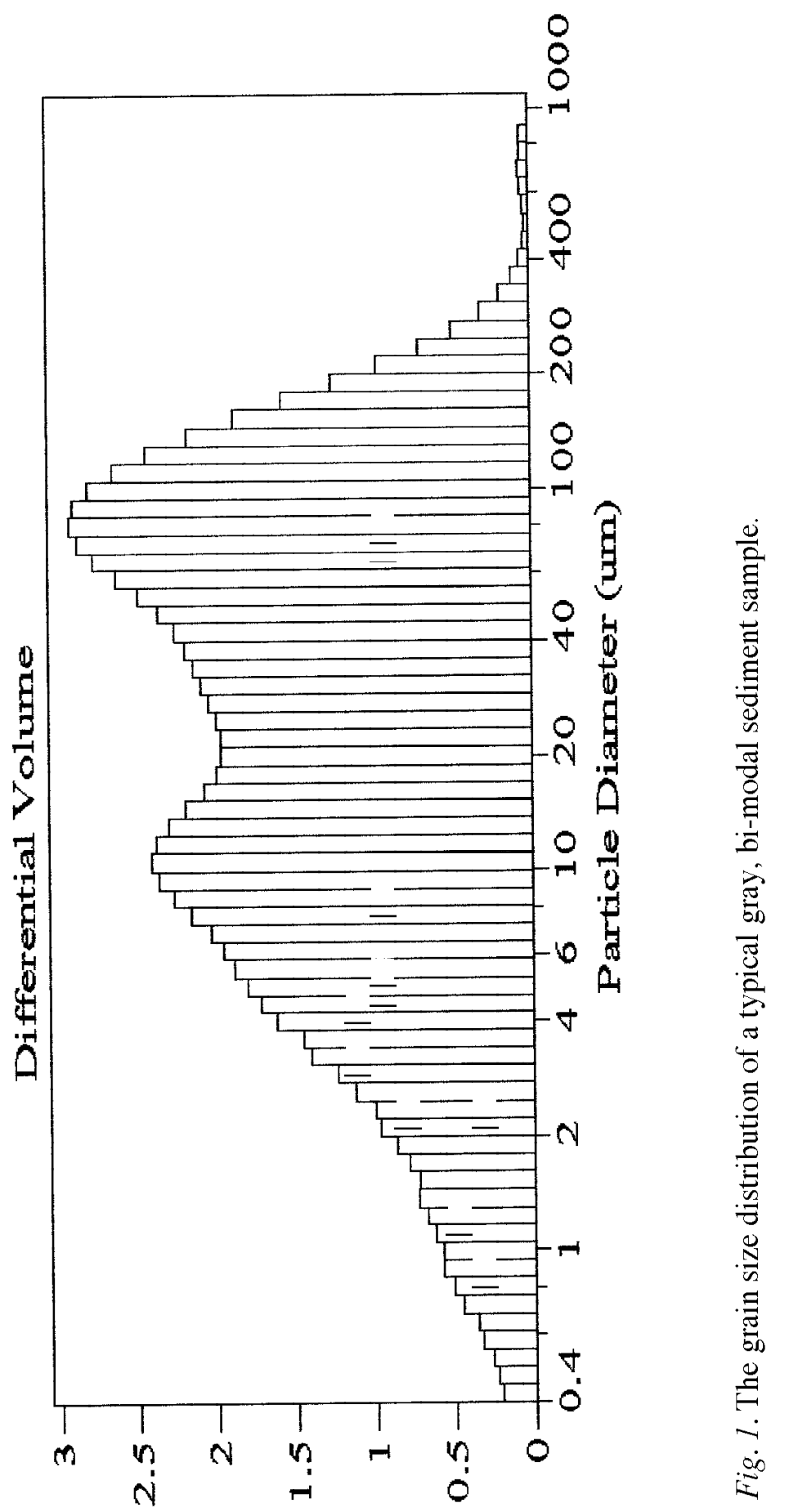

$\%$ əuัก门 $\Lambda$ 
dure was applied, using a protocol recommended by the Standard, Measurements and Testing Programme (SM\&T), formerly known as the European Communities Bureau of Reference (BCR) (Quevauviller et al. 1997; Mester et al. 1998; Quevauviller 1998). This protocol uses certified reference material (CRM) 601, which was developed to enable worldwide comparisons of test results from studies of metal-binding forms in sediment columns. (Quevauviller et al. 1997). Although there are problems in using results of sequential extraction to simulate natural processes (Martin et al. 1987), this procedure provides further insight into particulate fractions and more detailed information, with which to evaluate the transformation and mobility of metals in sediment columns.

Due to its isolation, GGL is only slightly affected by local anthropogenic activity (Wann et al. 1995; Wann and Chen 1996). The atmosphere provides most of the anthropogenic material found in the lake (Chen et al. 2001). Anthropogenic activity, such as the burning of fossil fuels, garbage and leaded gasoline, has significantly increased the flux of certain elements into the atmosphere (Li 1981; Patterson and Settle 1987; Nriagu 1989; Hsu et al. 2004). Consequently, this aeolian material has become the principal factor controlling distribution of a number of elements in the lake sediments. The wide variation in the total organic carbon content of sediments is another important factor which regulates the distribution of elements. This study examined the correlations between organic matter and other elements. Analysis of the distribution and forms of elemental species, as well as relationships among elements and organic carbon, was undertaken in this study to develop a better understanding of (1) the extent to which climate and other factors regulate the distribution of elements in sediments; (2) the relationships between metals and organic matter; and (3) the geochemical and diagenetic processes in a seasonally stratified and anoxic lake sediment column.

\section{STUDY AREA AND METHODS}

Located at $22^{\circ} 52^{\prime} \mathrm{N}, 120^{\circ} 51^{\prime} \mathrm{E}, \mathrm{GGL}$ is an oligo-mesotrophic body with an area of $11.25 \mathrm{ha}$, a volume of $1.67 \times 10^{6} \mathrm{~m}^{3}$ and an altitude of $2150 \mathrm{~m}$. It is the deepest $(40 \mathrm{~m}$; averaging $15.4 \mathrm{~m})$ and best preserved, natural lake in Taiwan. There is very little human perturbation at this remote location and due to an absence of wind mixing or bioturbation, the lake sediments are interlaminated and well preserved. Argillite and slate are the major types of rock, surrounding the lake.

A plastic barrel was the gravity corer used to collect sediment samples. Cored sediments were immediately sealed with wax, after recovery, and then processed at a laboratory, where fishing line was used to prevent any possible metal contamination (Chen et al. 1993). The extent of oxidation was negligible, as indicated by an absence of color change, when sediments were exposed during the process.

During the leaching procedure, $15 \mathrm{ml}$ of $1.6 \mathrm{~N}$ nitric acid was used to treat $0.3 \mathrm{~g}$ of dried sediment, which was shaken over night (Ng and Patterson 1982; Giblin et al. 1990) in a $50 \mathrm{ml}$ centrifuge tube. The leachate was separated by centrifugation, removed with a quartz pipette and stored in pre-cleaned polyethylene bottles until the metals were measured. To determine the total metal content, a microwave system with an acid mixture of $42 \% \mathrm{HNO}_{3}$ and $17 \% \mathrm{HF}$ 
was used to digest $0.3 \mathrm{~g}$ of dry sediment. ELAN 5000 Inductively Coupled Plasma-Mass Spectrometry (ICP-MS), coupled with a Ryton spray chamber and cross-flow nebulizer were used to measure metals. A peristaltic pump, with a flow rate of $1 \mathrm{ml} \mathrm{min}^{-1}$, was then used to nebulize sample solutions.

The LECO CS-244 elemental analyzer was used to determine total carbon (TC), total nitrogen (TN) and total sulfur (TS) content of sediments. LECO CS-244 elemental analyzer was also used to determine the total inorganic carbon content of sediment, after the samples were incinerated at $450^{\circ} \mathrm{C}$ for 6 hours to remove organic carbon. The content of total organic carbon (TOC) was taken to be TC-TIC. Wann et al. (1995) provided details on trace metal determination and the National Institute for Environmental Studies (NIES) No. 2 Pond Sediment (NOAA 1995) provided calibrations for each set of sample treatments and metal determinations, including those for the metalloid, As. The measurement of $\mathrm{Al}, \mathrm{As}, \mathrm{Cd}, \mathrm{Ce}, \mathrm{Cr}$, $\mathrm{Cs}, \mathrm{Cu}, \mathrm{Fe}, \mathrm{Mg}, \mathrm{Mn}, \mathrm{Ni}, \mathrm{Pb}, \mathrm{Rb}, \mathrm{Sr}, \mathrm{V}$ and $\mathrm{Zn}$ were roughly $\pm 15.9,10.7,7.3,9.5,8.4,7.1$, 3.2, 5.3, 4.5, 4.1, 2.1, 10.5, 4.1, 11.5, 1.7 and 3.8\%, respectively, based on replicate analysis.

A 3-step sequential extraction procedure (Mester et al. 1998) was used to determine metal contents of different fractions in sediments. According to Mester et al. (1998), the fractions of metal separated by the 3 -step procedure are i) the exchangeable/carbonatic fraction (Step 1), ii) the easily reducible fraction (Step 2), and iii) the oxidisable fraction (Step 3). $0.5 \mathrm{~g}$ of dry sample in a $50 \mathrm{ml}$ centrifuge tube was used in the procedure, with CRM 601 - lake sediment measured to control the quality of measurements. The tube was shaken at $45 \mathrm{rpm}$ for $16 \mathrm{hrs}$ with a vertical rotary shaker. The extract was separated by centrifugation at $10,000 \mathrm{rpm}$ for $30 \mathrm{mins}$ and was later removed with a quartz pipette to measure the metals with ICP-MS. Details of the sequential extraction steps mainly followed Mester et al. (1998).

\section{RESULTS AND DISCUSSIONS}

$93 \mathrm{~cm}$ core was collected from the middle of GGL was studied. Lake cores collected, exhibited a distinctive lamination and correlated well with each other.

\subsection{Organic Carbon and Weather Pattern}

Distribution of TC, TN, TS, TC/TN ratio and water content in sediments are shown in Fig. 2. Since the content of inorganic carbon was usually very small (less than $0.2 \%$ ), the TC measured was nearly equal to the total organic carbon (TOC). Low TC values correlated well with brighter sediments, whereas higher values correlated with darker ones. TC content vary markedly from 2.0 to $19.3 \%$. With a few exceptions, the TC-values generally increased with depth. This was in direct contrast to the usual trend that was found in the shallow and oxic Little Ghost Lake, in the same area (Lin 1992). Kuivila and Murray (1984) and Birch et al. (1996) showed that total organic carbon decreases with depth as a result of decomposition and remineralization of buried organic matter.

The variation in the TC content of sediments in GGL was generally a result of the variation in particulate input. Chen et al. (1993) and Lou et al. (1997) reported that the brighter 


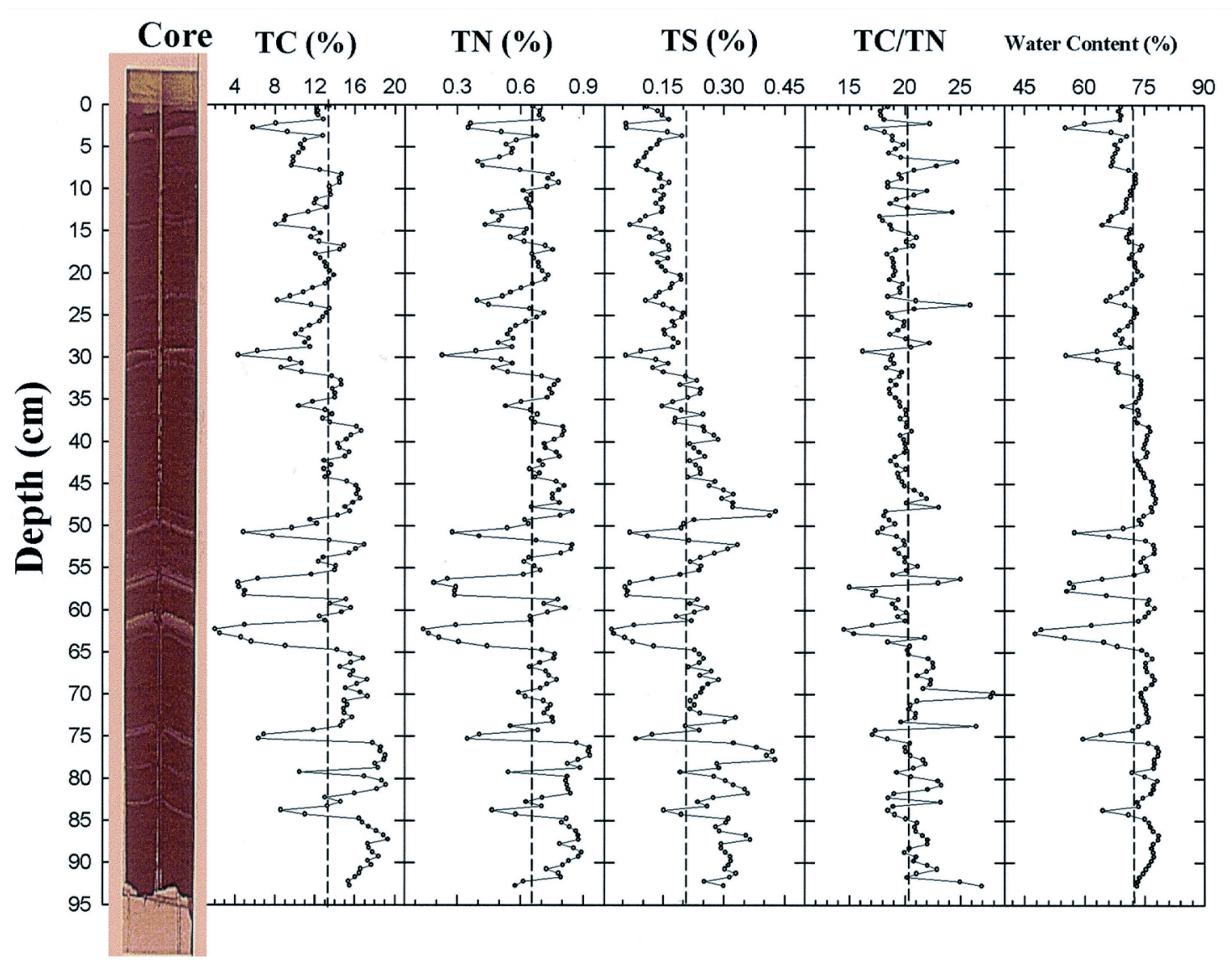

Fig. 2. Distribution of total carbon (TC), total nitrogen (TN), total sulfur (TS), TC/TN ratio and water content in the sediments of GGL (modified from Lou et al. 1997).

sediments, with lower TC and smaller particle size, were consistent with cool, dry periods, while darker sediments, with higher TC and larger particle size, correlated with warm, wet periods. During dry periods, when water levels were low, less TC particles entered sediments from the shore, leading to lower TC values (Chen et al. 1993; Lou et al. 1997). At the same time, the aquatic carbon with relatively low TC/TN ratios, of about 10, (Huang 1992; Huang and Chen 1994) became significant sources of TC. In addition, lower lake water volume, during dry periods, might have increased concentrations of nutrients, which resulted in larger numbers of aquatic organisms in water and sediments and lead to lower TC/TN ratios in sediments. 
During wet periods, TC content of soil from the catchment area was high and the soil became the major source of sediments, with high TC content. The TC/TN ratios of terrestrial plants in this area were about $26-30$. Consequently, the TC/TN ratio was also higher in the sediments deposited, during wet periods. This finding was supported by a good positive correlation between TC and TC/TN (Fig. 3). The TN and TS content ranged from $0.14 \%$ to $0.93 \%$ (averaging $0.65 \%$ ) and from $0.02 \%$ to $0.43 \%$ (averaging $0.21 \%$ ), respectively. The water content ranged from $47.6 \%$ to $78.5 \%$ (averaging $72.0 \%$ ). Figure 3 reveals strong positive correlations between TN, TS and TC, and the intercepts of the regression lines are very close to zero. Since TC is nearly equal to the TOC, this implies that carbon, in sediments, and perhaps nitrogen and sulfur as well, were mainly derived from organic sources, including aquatic and terrestrial ones. A high positive correlation between TC and water content is also shown in Fig. 3. This might have been due to increased porosity of organic matter.

Terrestrial and aquatic plants have different $\mathrm{C} / \mathrm{N} / \mathrm{S}$ ratios, with terrestrial plants having higher TS but lower TN content, when compared with aquatic plants. In this study, the TC/TN ratio was found to increase, whereas the TC/TS ratio was found to decrease as TC increased (Fig. 3). A high TC/TN ratio with a low TC/TS ratio when TC content was high implies that in warmer periods (higher TC), the amount of organic matter supplied to the sediments by terrestrial plants increased. For the same reason, TS/TN ratio was also higher when TC content was higher (Fig. 3). Furthermore, anoxic conditions during warm, wet periods might lead to higher TS content in sediments due to sulfide mineral deposition.

\subsection{Factors Regulating Metal Deposition}

Distribution of TC and total metals for dry weight is shown in Fig. 4. Most metal concentrations were similar to those found in other lakes (Forstner and Wittmann 1983; Das et al. 1995; Birch et al. 1996) and to standard values in shale (Turekian and Wedepohl 1961). Figure 4 shows that $\mathrm{Al}, \mathrm{Cs}, \mathrm{Fe}, \mathrm{Mg}, \mathrm{Ni}, \mathrm{Rb}$ and $\mathrm{V}$ have a negative correlation with $\mathrm{TC}$ content.

Correlation amongst elements was supported by correlations between total metals and TC content shown in Table 1. The negative correlation coefficient between Al-TC, Cs-TC, FeTC, Mg-TC, Ni-TC, Rb-TC and V-TC was good for each. However, the same metals also had good positive correlations with each other (Table 1). This trend suggests that $\mathrm{Al}, \mathrm{Cs}, \mathrm{Fe}, \mathrm{Mg}$, $\mathrm{Ni}, \mathrm{Rb}$ and $\mathrm{V}$ in sediments were derived mainly from lithogenic sources and were diluted by deposition with organic matter. Chemical forms of metals determined by sequential extraction from the sediment column have confirmed this finding (Fig. 5). These metals occurred mainly in the residual fraction (total metal content for the sum of the three components obtained from the 3-step extraction procedure) and mostly in the hard-to-reduce fractions such as that for refractory organic matter and within a crystal structure of primary and secondary minerals. The majority of primary and secondary minerals in sediments were quartz, feldspars and clay minerals (Chen et al. 1993).

Few metals, with the exception of $\mathrm{Fe}$ and $\mathrm{Ni}$, occurred in the mobile fractions of sediments, i.e., exchangeable/carbonatic, easily reducible and oxidisable fractions. This finding was similar to that of Mester et al. (1998). Metals in these fractions represented sorbed, precipitated or coprecipitated (on carbonates, hydrous Fe/Mn oxides and sulfides) and complex forms in 

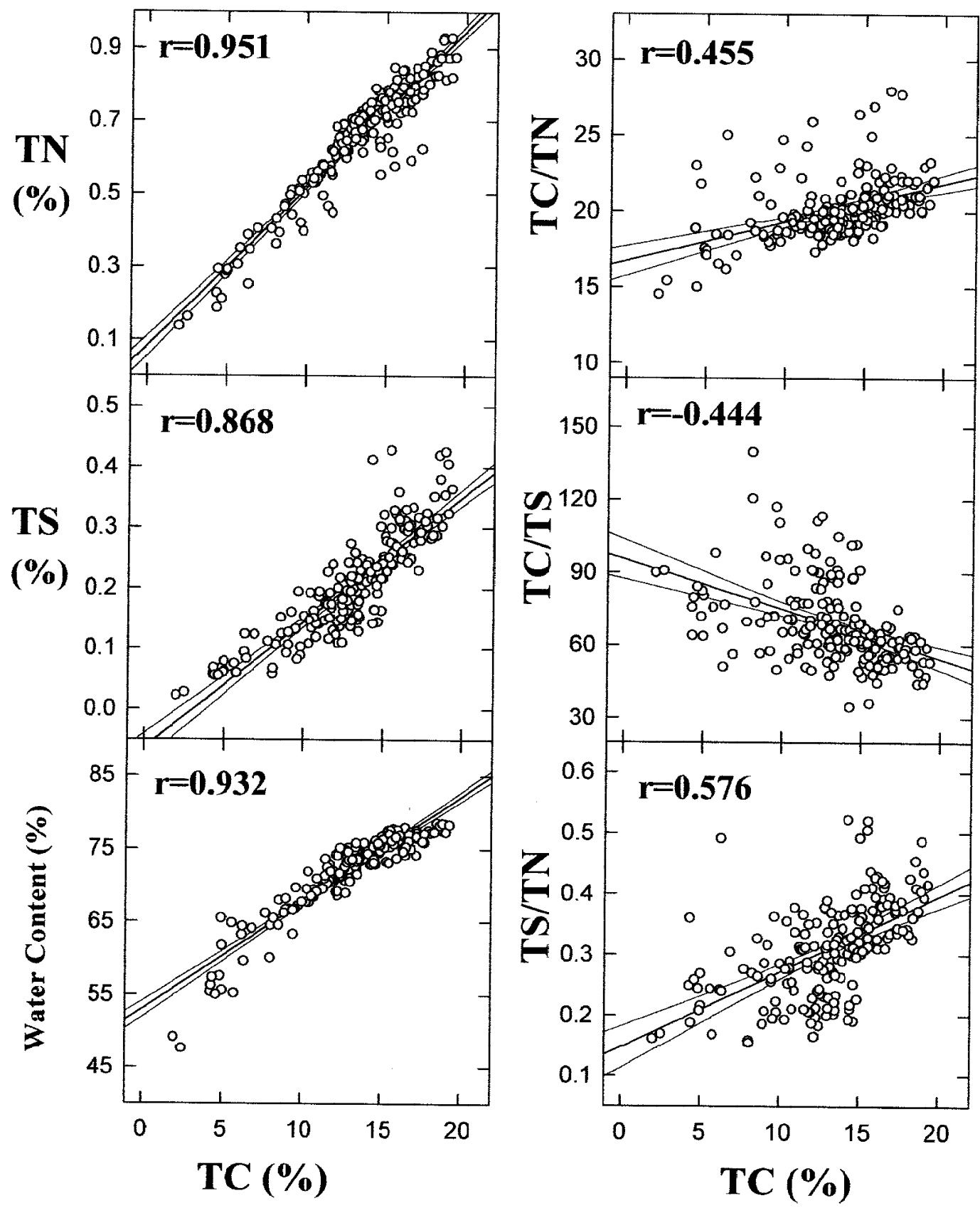

Fig. 3. Correlations between total carbon (TC) and total nitrogen (TN), total sulfur (TS), water content, TC/TN, TC/TS and TS/TN in the sediments of GGL. The regression line and its $95 \%$ confidence range are marked. 

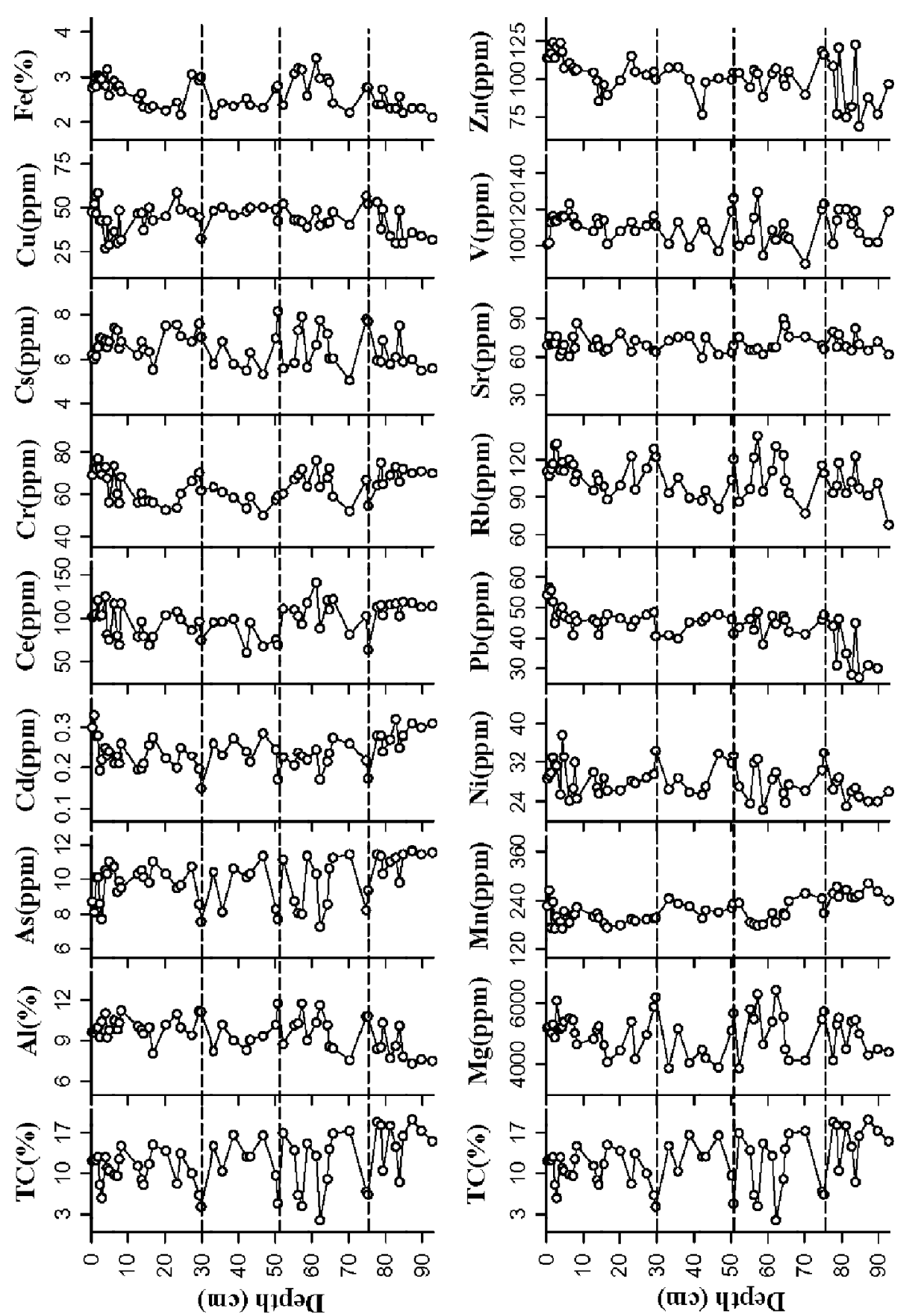

放융

คิ

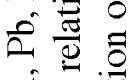

元参言

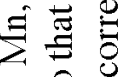

oî ह

$\sum \frac{n}{ \pm}$

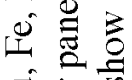

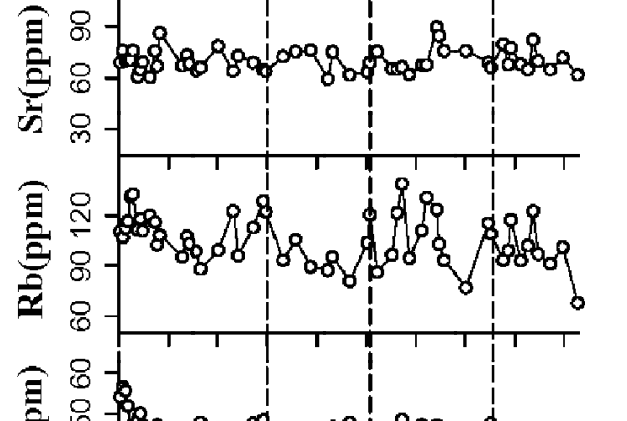

$\tilde{\mathrm{U}} \overline{\mathrm{D}}$

के

记芯

仓ัす

j

U.

市

胥

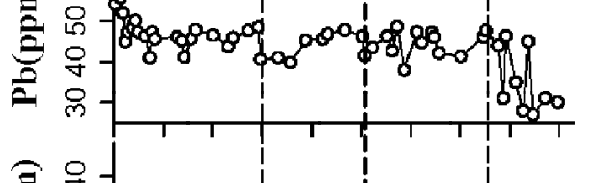

䆑言

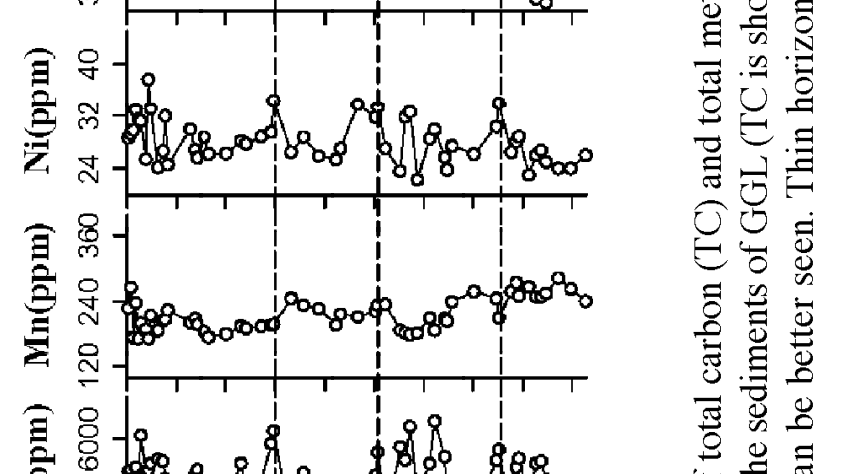

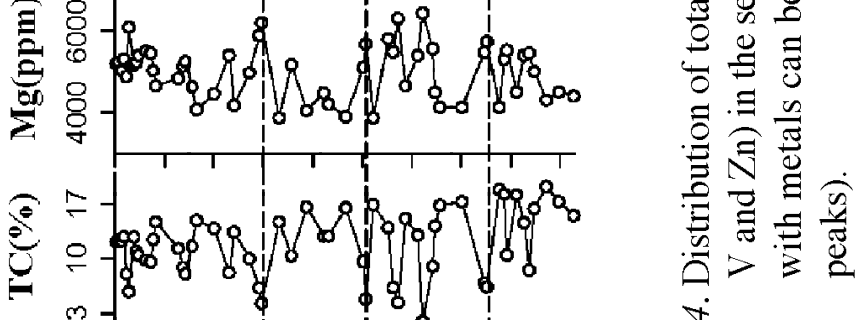

- m-1,

(uiv) y1da( 


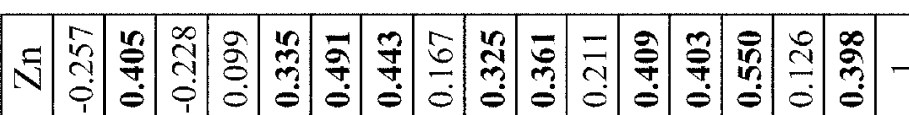

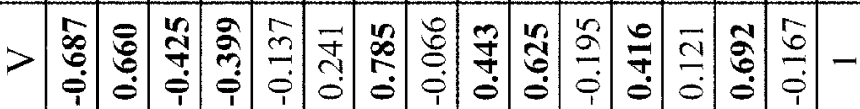

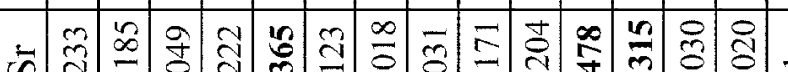

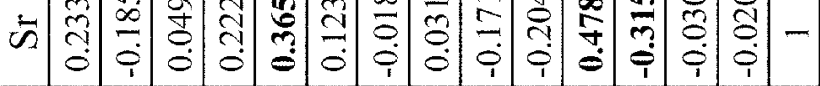

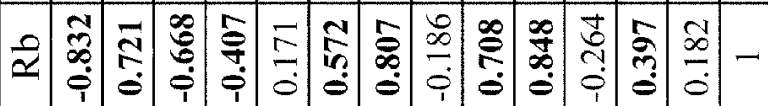

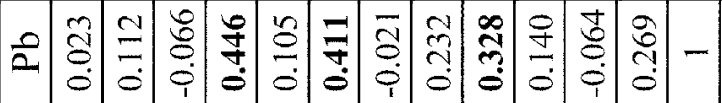

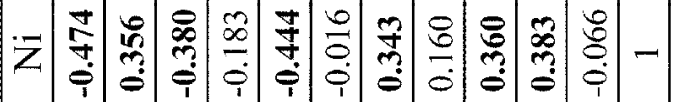

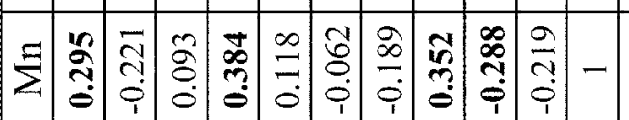

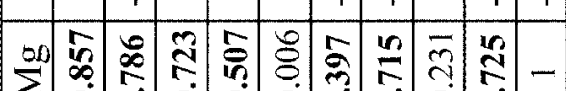

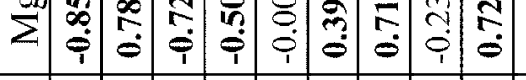

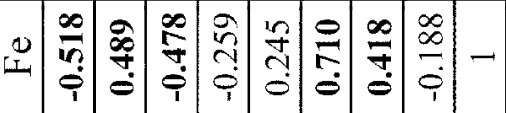

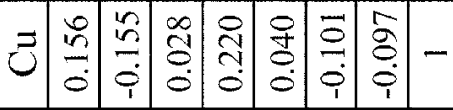

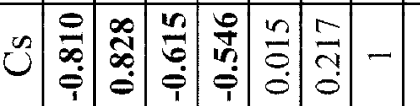

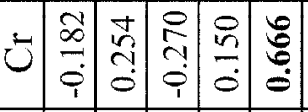

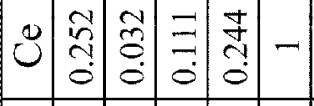

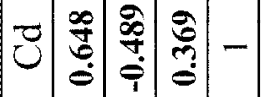

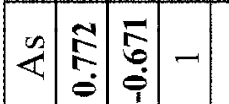

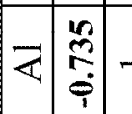

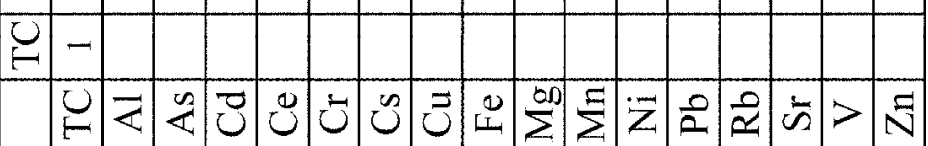


sediments, which were probably affected by diagenesis and/or changes in water chemistry. A significant portion of $\mathrm{Fe}$ initially occurred as mobile Fe oxides. Anoxic conditions in sediments produced reductive dissolution of $\mathrm{Fe}$ (III) oxides and thereafter, dissolved $\mathrm{Fe}^{2+}$, which could interact with the other species, especially organic substances. This interaction could transform Fe from easily reducible fractions to oxidisable forms and account for large amounts of Fe observed in the oxidisable fraction (Fig. 5).

As $(r=0.772)$ and $\mathrm{Cd}(\mathrm{r}=0.648)$ displayed good positive correlations with TC content. The correlation coefficient between As and $\mathrm{Cd}(\mathrm{r}=0.369)$ was low, butstill significant (Table 1). The chemical forms of metals derived from sequential extraction could also explain these results (Fig. 5). Figure 5 reveals that large amounts of these two metals were in mobile fractions. As also occurred in residual fractions, and since it occurred in oxidisable fractions as well, a complex or incorporation of As, with the organic matter was evident. $\mathrm{Cd}$, on the other hand, is chiefly observed in exchangeable/carbonatic fractions, indicating $\mathrm{Cd}$ was sorbed with organic matter.

Total $\mathrm{Ce}, \mathrm{Cr}, \mathrm{Cu}, \mathrm{Pb}, \mathrm{Sr}$ and $\mathrm{Zn}$ concentrations did not correlate with $\mathrm{TC}(\mathrm{r}<0.26$; Table 1). Total $\mathrm{Ce}, \mathrm{Cu}, \mathrm{Mn}, \mathrm{Pb}$ and $\mathrm{Sr}$ did not have significant correlations with metals from lithogenic sources (Table 1), which suggests that few of these metals were associated with both organic and inorganic mobile fractions of sediments. On the other hand, total $\mathrm{Cr}$ and $\mathrm{Zn}$ had significant positive correlations with metals from mainly lithogenic sources (Table 1), which suggests that $\mathrm{Cr}$ and $\mathrm{Zn}$ were associated with inorganic minerals in sediments. Surface sediment was enriched with $\mathrm{Cd}$ and $\mathrm{Pb}$ (Fig. 4). Enhanced concentrations of $\mathrm{Cd}$ and $\mathrm{Pb}$ were also reflected in their correlations with TC (Table 2). The source of these metals was probably from anthropogenic, aeolian particles. Anthropogenic input of $\mathrm{Pb}$ has been previously reported, as indicated by a low $\mathrm{Pb}-206 / \mathrm{Pb}-207$ ratio in surface sediment (Wann et al. 1995; Wann and Chen 1996).

Distribution of total carbon and acid-leached metals (extracted with $1.6 \mathrm{~N} \mathrm{HNO}_{3}$ ) is shown in Fig. 6. Acid-leached $\mathrm{As}, \mathrm{Cd}, \mathrm{Cr}, \mathrm{Cu}, \mathrm{Mn}, \mathrm{Sr}$ and $\mathrm{V}$ showed significant positive correlations with TC, as well as with most metals (Table 2), which suggests that these acidleached metals were associated mainly with organic matter. With the exception of residual fractions, As, $\mathrm{Cr}$ and $\mathrm{Cu}$ occurred mainly in oxidisable fractions (Fig. 5), so they might be a complex of or incorporated into organic matter, and this could explain positive correlation coefficients between TC and these metals (Table 2). Since Cd, Mn and Sr were mainly in exchangeable/carbonatic fractions, they could be sorbed with organic matter. Correlation between acid-leached metals, $\mathrm{Al}, \mathrm{Cs}, \mathrm{Mg}, \mathrm{Ni}$ and $\mathrm{Rb}$, were positive with each other but were negative with TC (Table 2). Most of these metals were in the residual and oxidisable fractions (Fig. 5), suggesting that acid-leached $\mathrm{Al}, \mathrm{Cs}, \mathrm{Mg}, \mathrm{Ni}$ and $\mathrm{Rb}$ in sediments were mainly associated with mobile inorganic phases.

Concentration of metals in mobile fractions (Step1 + Step2 + Step3; Fig. 5) and in acidleached fractions (Fig. 6) compared well, except for $\mathrm{Al}, \mathrm{Ce}, \mathrm{Cs}$ and $\mathrm{Cu}$. Concentrations of these in acid-leached fractions were about three times that of mobile fractions. This indicates that large amounts acid-leached content of these four metals could not be released by the 3step procedure. A large amount of $\mathrm{Al}(\sim 1.3 \%)$, which has a significant negative correlation $(\mathrm{r}=-0.288$; Table 2$)$ with TC, was found in acid-leached fractions. This finding suggests that 


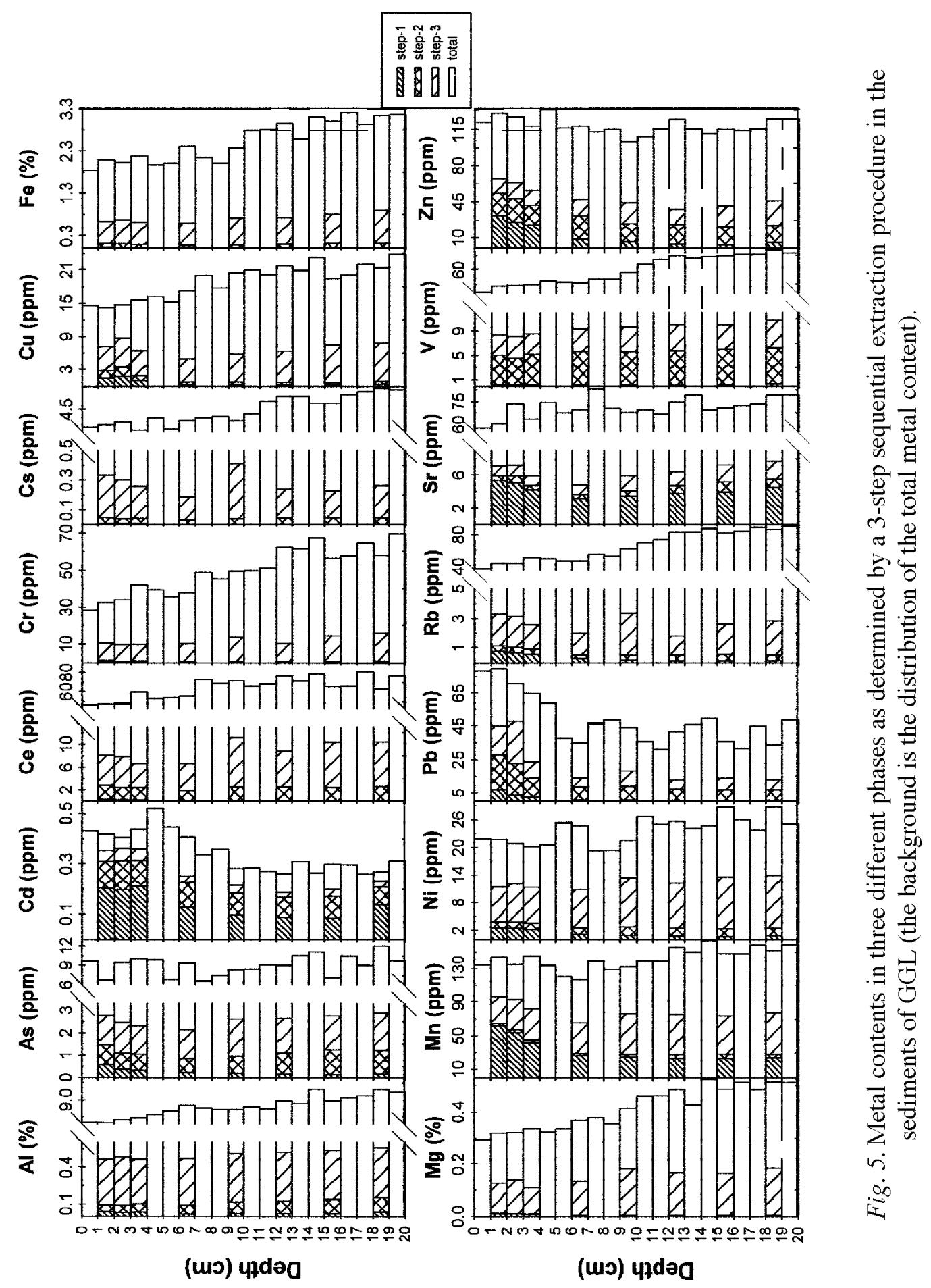


Al was mainly associated with other mobile inorganic fractions, such as $\mathrm{Al}$ hydroxides and oxyhydroxides, that are usually found in soil minerals synthesized during pedogenesis. Large amounts of acid-leached $\mathrm{Ce}, \mathrm{Cs}$ and $\mathrm{Cu}$ might also be associated with the $\mathrm{Al}$ hydroxides and oxyhydroxides. The acid-leached concentration of metals represented most of the metal content in mobile fractions of sediments, and were more readily determined using this method than by sequential extraction. As a result, large numbers of samples could be analyzed quickly. Sequential extraction provided more detail but this procedure was tedious, which limited the number of samples that could be analyzed.

The correlations between TC and acid-leached Fe (about $40 \%$ of total Fe content) were not significant at $\alpha=0.05$ (Table 2), but large amounts of Fe content (about $30 \%$ of total $\mathrm{Fe}$ ) was found in oxidisable fractions (Fig. 5), which was the main fraction represented. Acidleached Fe probably contained oxidisable fractions, at least in part, and/or other organic fractions that could not be released by sequential extraction. However, complicated interactions between $\mathrm{Fe}^{2+}, \mathrm{Fe}$ (III) oxides, organic substances and clay particles in the water column and sediments can also result in associations of Fe and organic carbons (Tipping 1981; Forstner and Wittmann 1983; Salomons and Forstner 1984; Wann and Chen 1996; Wann et al. 1997). This could also explain why large amounts of Fe were found in oxidisable fractions and correlations between TC and acid-leached Fe were positive. Negative correlations between TC and total $\mathrm{Fe}$ were found because $\mathrm{Fe}$ was mainly derived from lithogenic sources and exists in residual fractions (Fig. 5). Lithogenic and organic matter were the two major components of sediments and an increase in one must be accompanied by a decrease in the other.

Poor correlations between TC and total and acid-leached $\mathrm{Ce}, \mathrm{Pb}$ and $\mathrm{Zn}$ were found in sediments $(r=0.252$ and 0.162 for $\mathrm{Ce}, \mathrm{r}=0.023$ and -0.257 for $\mathrm{Pb}, \mathrm{r}=-0.100$ and 0.153 for $\mathrm{Zn}$, respectively). In this case, poor correlations occurred mainly because more than $50 \%$ of total metal content was in residual fractions, except for a few surface samples. Small amounts of $\mathrm{Pb}$ and $\mathrm{Zn}$ were found in oxidisable fractions, which was even less than that for the other two mobile fractions, and explain poor correlations between their acid-leached values and TC. Figure 5 shows that, with the exception of residual fractions, $\mathrm{Ce}, \mathrm{Pb}$ and $\mathrm{Zn}$ were mainly in easily reducible and oxidisable fractions. Figure 5 shows that surface enrichment of $\mathrm{Zn}$ (not obvious in $\mathrm{Pb}$ ) was also found in exchangeable/carbonatic fractions.

Distribution of acid-leached $\mathrm{Cd}$ and $\mathrm{Pb}$ (Fig. 6) and their correlations with TC (Table 2) also demonstrated enrichment near the surface. This was mainly due to atmospheric anthropogenic input (Wann et al. 1995; Wann and Chen 1996). Surface enrichment of Pb due to atmospheric anthropogenic input was mainly found in easily reducible fractions. Results derived from the study of a water column in which the annual Fe cycle plays a major role as a sink for atmospheric $\mathrm{Pb}$ (Wann et al. 1997), supports findings from this study.

The relationship between total metals and total carbon and acid-leached metal/total metal (extractable ratios) are shown in Fig. 7. In sediments $\mathrm{Al}, \mathrm{Cs}, \mathrm{Mg}, \mathrm{Rb}$ and $\mathrm{V}$, possess low extractable ratios, which clearly correlate negatively with TC (or TOC). These metals were relatively stable in this environment and occurred mainly in immobile fractions of sediments, i.e., in mineral lattices and in refractory organic matter. Relatively mobile metals, on the other hand, were associated with higher extractable ratios and higher organic carbon content.

The correlation coefficient between total V and TC was negative (-0.69), but the correla- 


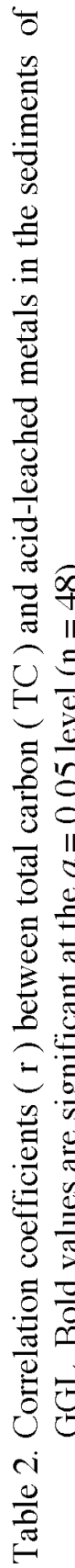

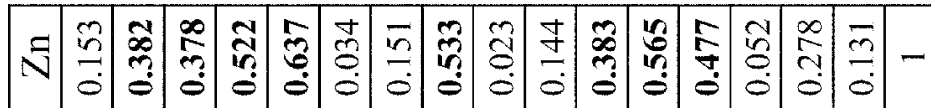

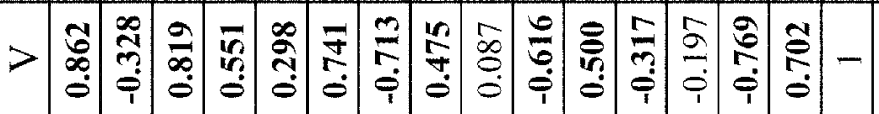

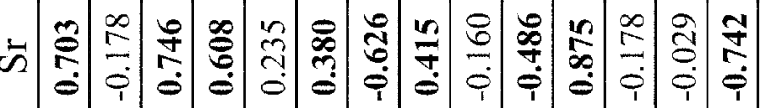

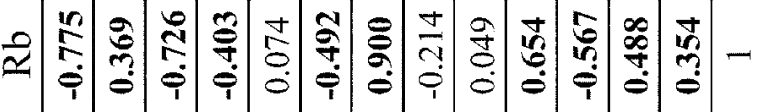

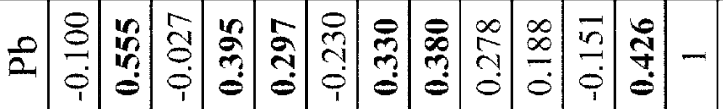

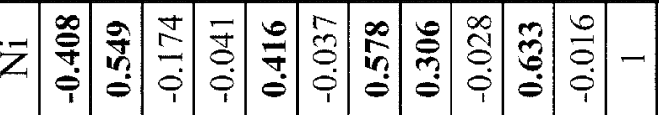

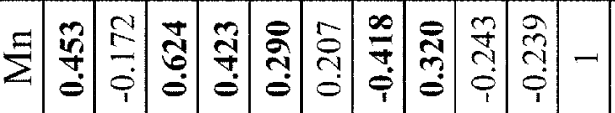

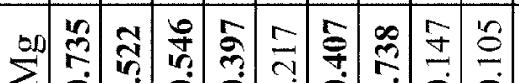

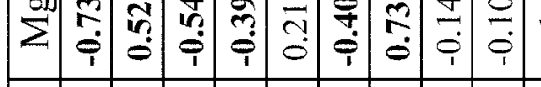

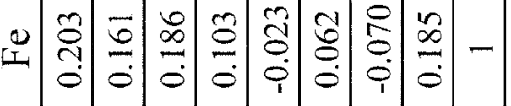

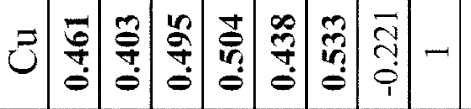

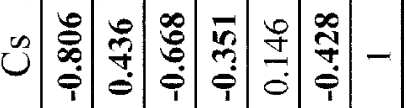

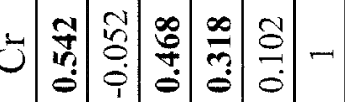

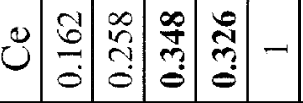

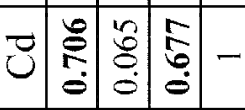

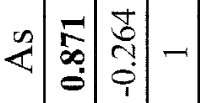

之 \begin{tabular}{c}
$\infty$ \\
\multirow{4}{*}{} \\
0 \\
$i$
\end{tabular} \mid

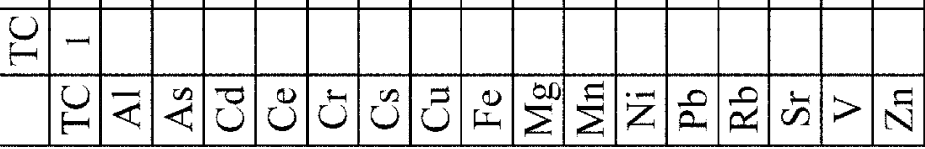



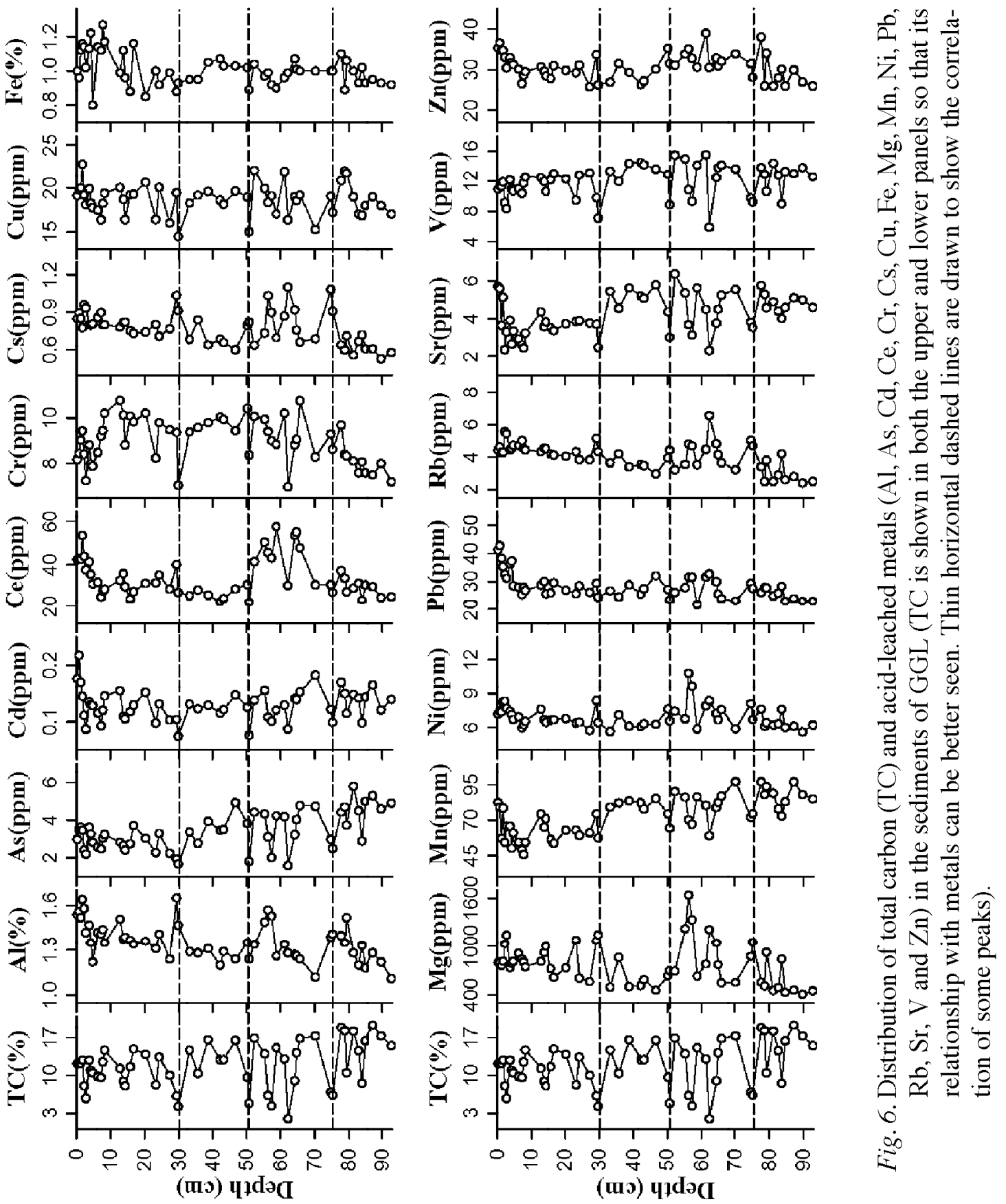
tion coefficient changed to positive (0.862) between acid-leached V and TC. This high correlation contradicts that of other immobile metals, especially $\mathrm{Cs}$ and $\mathrm{Rb}$, whose total and mobile fractions negatively correlated with TC. It is not known if acid leachable V has a broader source base during drier periods (lower TC). On the other hand, certain processes could explain differences between $\mathrm{V}$ and other conservative, nonmobile metals. Weathering of exposed rocks could oxidize $\mathrm{V}^{3+}$ to $\mathrm{VO}_{4}{ }^{3-}$, a highly soluble species in oxic water. In anoxic

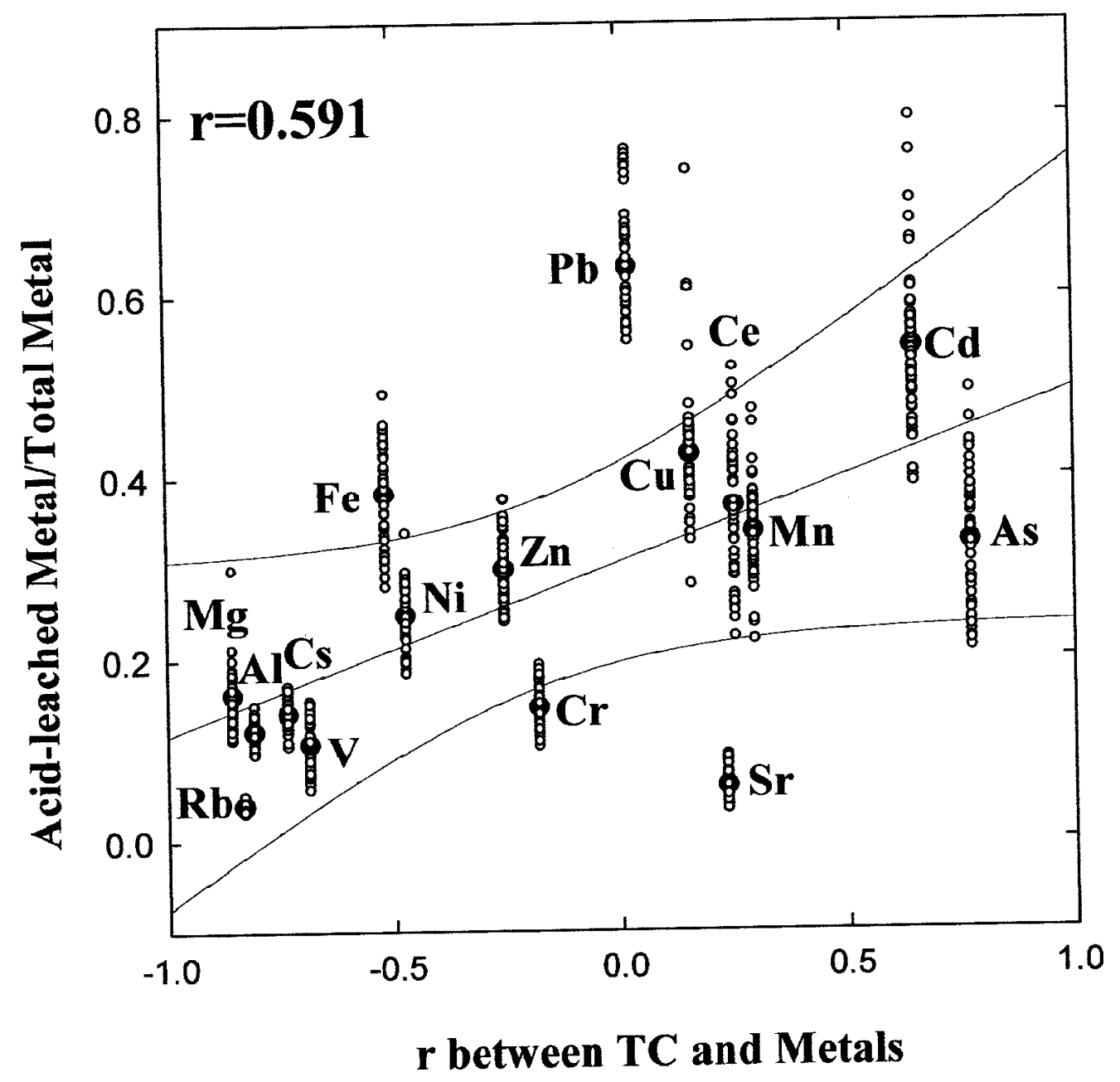

Fig. 7. Correlation between the ratios of acid-leached metal/total metal and the correlation coefficients (r) of total carbon and total metals. The r egression line obtained from the average of acid-leached metal/total metal and its $95 \%$ confidence range are marked. 
water, $\mathrm{VO}_{4}{ }^{3-}$ is transformed into $\mathrm{VO}^{2+}$ which is easily associated with particles (Premovic et al. 1993). Since the Great Ghost Lake is seasonally stratified and anoxic, dissolved $\mathrm{VO}_{4}{ }^{3-}$ can be transformed into $\mathrm{VO}^{2+}$ during anoxic stratification and then combine with organic matter or other surface particles in anoxic bottom waters. The reduction of $\mathrm{VO}_{4}{ }^{3-}$ to $\mathrm{VO}^{2+}$ by humic substances under anoxic conditions, with subsequent formation of vanadyl organic complexes, has been demonstrated previously (Wilson and Weber 1979; Templeton III and Chasteen 1980; Francois 1988). In addition to effects of changing water redox conditions, sediment input and water redox conditions in GGL were also highly influenced by climatic changes. During warm, wet periods, high water level and increased water stratification enhanced anoxic conditions and resulted increased $\mathrm{VO}^{2+}$ being incorporated into high-TC sediments. In contrast, during cool, dry periods, little $\mathrm{VO}^{2+}$ was transformed to associate with the low-TC sediments in oxic conditions. Low $\mathrm{V}$ was observed in oxidisable fractions in low-TC sediments, whereas high $\mathrm{V}$ was observed in oxidized fractions in high-TC sediments.

Distributions of total carbon and acid-leached $\mathrm{Mn}$ and their relationships in sections from 0 to $30 \mathrm{~cm}$ and from 30 to $84 \mathrm{~cm}$ are shown in Fig. 8 . In the upper $30 \mathrm{~cm}$ of sediments, the average acid-leached $\mathrm{Mn}$ concentration ( $62.6 \mathrm{ppm})$ was lower than those in deeper layers $(\sim 79.3 \mathrm{ppm})$, with poor negative correlations with carbon $(\mathrm{r}=-0.13)$. In contrast, there was good positive correlation $(\mathrm{r}=0.88)$ between organic carbon content and acid-leached $\mathrm{Mn}$ in sediments below $30 \mathrm{~cm}$. Both $\mathrm{Mn}$ and $\mathrm{Fe}$ are redox-sensitive elements. The acid-leached $\mathrm{Mn}$ in the sediments represented most of mobile fractions (Step1 + Step2 + Step3) and contained the entire exchangeable/carbonatic fraction. Abundance of $\mathrm{Mn}$ indicated that $\mathrm{Mn}$ recycle was an important geochemical process in the lake. During warm climatic conditions and high water levels, the development of a thick anoxic hypolimnion favored release of $\mathrm{Mn}$ from shallower sediments to the water column. Marked Mn was found in the water column as shown in Fig. 10. High Mn concentrations in deeper parts of the water column were affected by input of reduced Mn from bottom sediments, during summer (May 1993 and July 1988). On the other hand, Fe was mainly affected by diffusion of reduced iron from bottom sediments since Fe oxides are reduced at lower redox potentials.

During the winter turnover, Fe oxides were formed in the water column, removing dissolved reduced Mn. Distribution of Mn in one winter is shown in Fig. 9a and that in March 1992, is shown in Fig. 10. During the development of anoxic hypolimnion, Mn, removed by Fe oxides, was re-dissolved into water, where it could interact with $\mathrm{CO}_{3}{ }^{2-}$ to produce $\mathrm{MnCO}_{3}$ (rhodochrosite). This compound was usually found in anoxic sediments during early diagenesis (Berner 1981; Surdam et al. 1984; Sigg et al. 1991). Large amounts of Mn observed in exchangeable/carbonatic fractions (Fig. 5) supports the notion of $\mathrm{MnCO}_{3}$ production. In addition, Ksp calculations of $\mathrm{Mn}$ species also suggest that Mn concentrations in anoxic bottom waters of GGL were limited by solubility of $\mathrm{MnCO}_{3}$ during late stage stagnation (Wann et al. 1997). $\mathrm{MnCO}_{3}$ was stable in sediments and did not participate in the redox cycle again. All this led to high content acid-leached Mn in high-organic-matter sediments produced during the warm, wet periods.

As for the cold, dry periods, climatic conditions and low water levels were not suitable for development of anoxic hypolimnion and release of Mn from sediments (Fig. 9b). As a result, less recycled Mn was found in white layers and sediments from $29.5 \mathrm{~cm}$ to about $2 \mathrm{~cm}$. These 
climatic conditions also led to low production of $\mathrm{CO}_{3}{ }^{2-}$ and $\mathrm{MnCO}_{3}$. Accordingly, mobile fractions of $\mathrm{Mn}$ in sediments did not increase but, in fact, decreased such that a negative correlation existed between acid-leached Mn and TC. Sediments from 29.5 to $2 \mathrm{~cm}$ were deposited from about the 13th to late 19th century (Lou et al. 1997), around the time of the "Little ice Age". More recently, however, climatic conditions have become warmer, and higher acidleached Mn was also found in sediments above $2 \mathrm{~cm}$.

Distribution of acid-leached Sr (Fig. 11) was similar to that of acid-leached Mn in sediments, and their positive correlation was quite substantial at $r=0.875$ (Table 2). In the upper $29.5 \mathrm{~cm}$ of sediments, acid-leached $\mathrm{Sr}$ content was also lower than that in deeper layers. Its correlation with TC was also poor $(r=0.273$, where $r$ is 0.07 if samples above $2 \mathrm{~cm}$ are excluded). There was however strong positive correlations $(\mathrm{r}=0.956)$ between TC and acid-leached Sr in sedi-
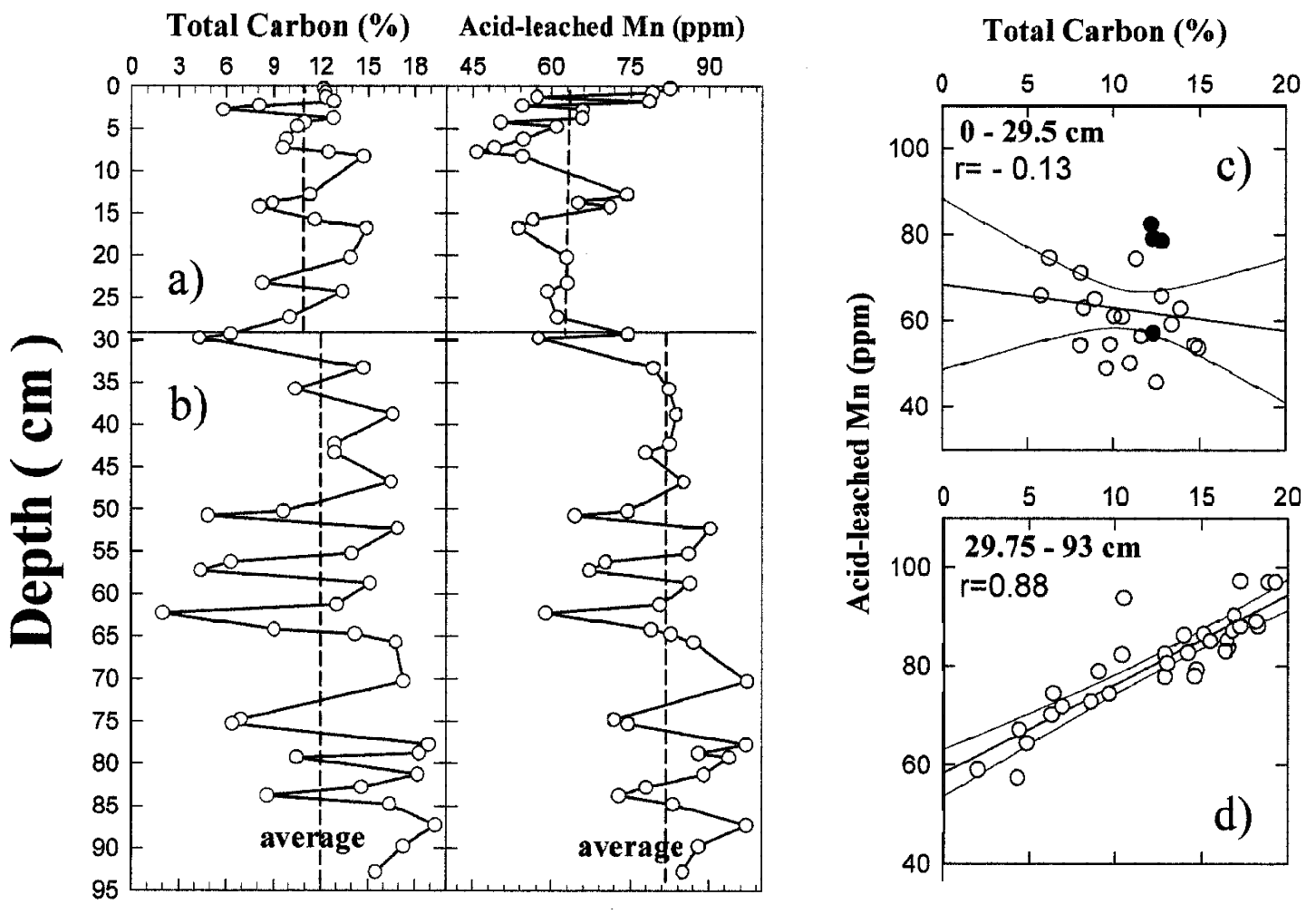

Fig. 8. Distribution of total carbon and acid-leached $\mathrm{Mn}$ in the sediments of GGL from (a) 0 to $30 \mathrm{~cm}$ and from (b) 30 to $93 \mathrm{~cm}$, as well as correlations between total carbon and acid-leached $\mathrm{Mn}$ from (c) 0 to $30 \mathrm{~cm}$ and from (d) 30 to $93 \mathrm{~cm}$. Dark circles represent those above $2 \mathrm{~cm}$; $r$ is -0.40 if these 4 points are excluded. The regression line and its $95 \%$ confidence range are marked. 

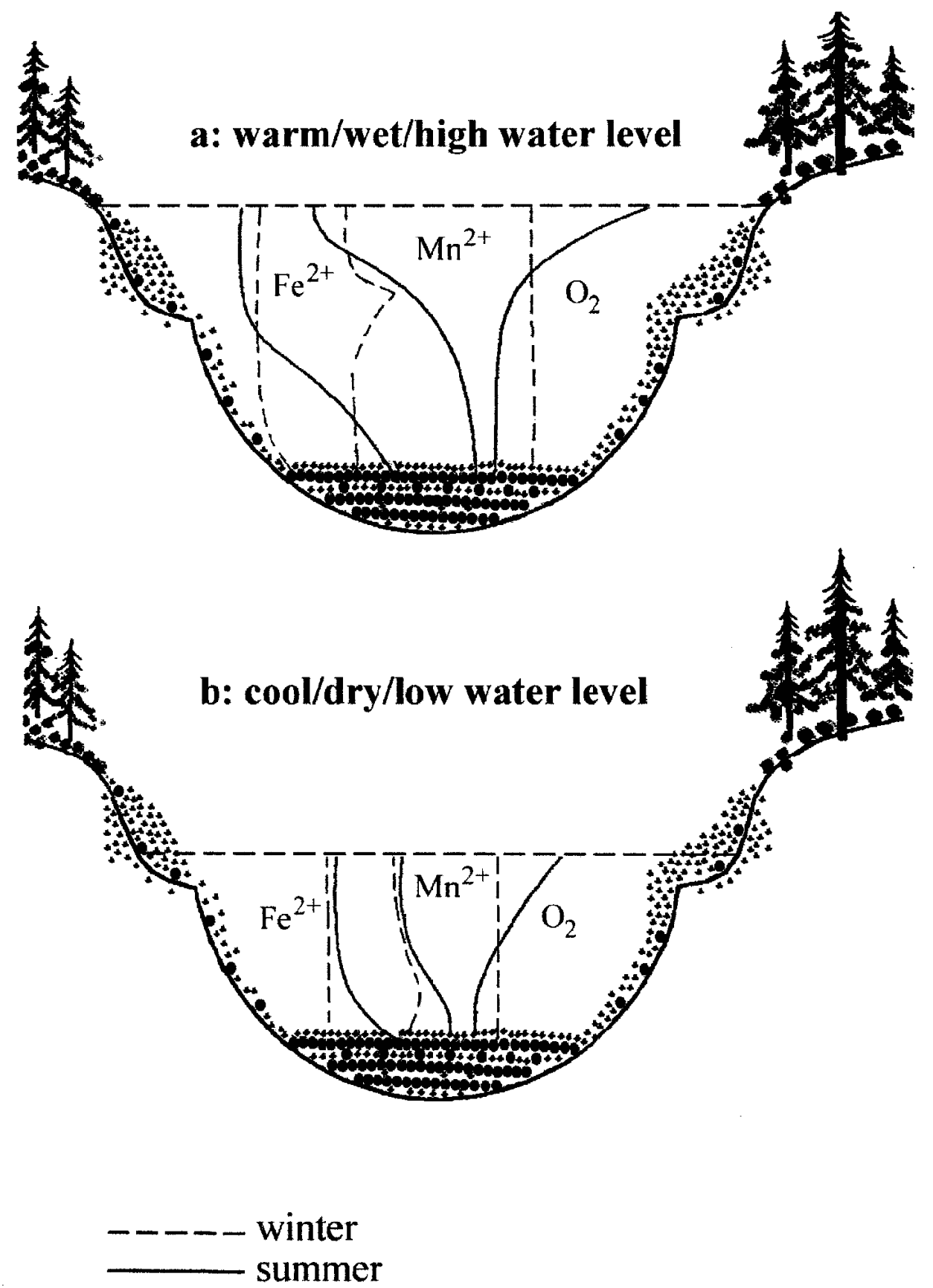

Fig. 9. Hypothetical distribution of dissolved oxygen, $\mathrm{Fe}^{2+}$ and $\mathrm{Mn}^{2+}$ in summer and winter in GGL during the (a) warm/wet and (b) cool/dry periods. 


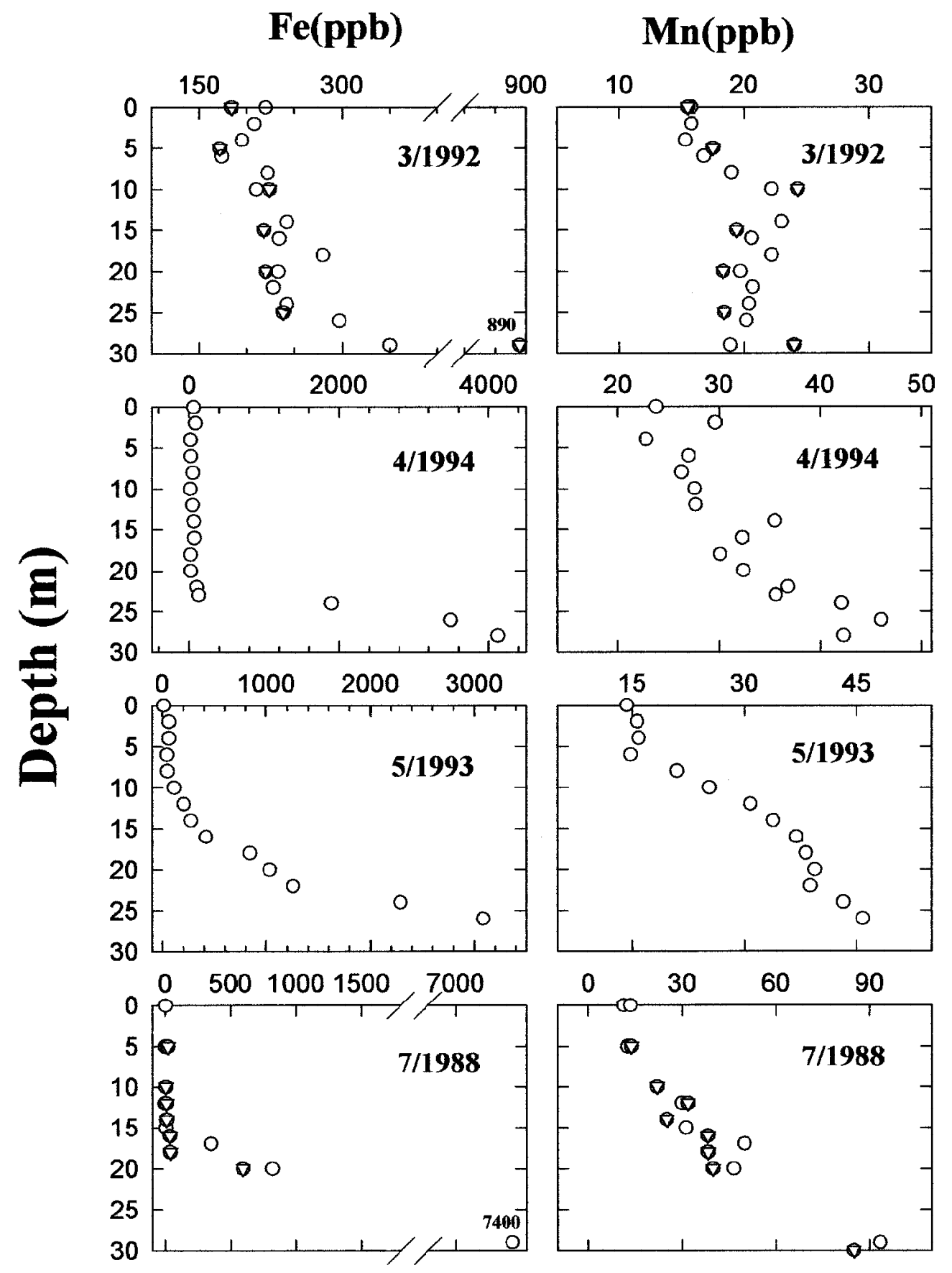

Fig. 10. Distribution of total dissolved Fe and Mn in GGL, where circles and triangles are the results obtained from different stations. Note the change in scales (taken from Wann et al. 1997). 
ments below $29.5 \mathrm{~cm}$. Sr is a IIA element with a strong tendency to form $\mathrm{SrCO}_{3}$ and formation was similar to $\mathrm{MnCO}_{3}$ in sediments. Similarities between $\mathrm{Mn}$ and $\mathrm{Sr}$ were even closer when their distributions in mobile fractions were examined (Fig. 5).

To summarize, long-term variations in redox conditions in the lake were mainly controlled by local climate changes. A surplus of $\mathrm{Mn}, \mathrm{Sr}$ and $\mathrm{V}$ were incorporated into high-TC sediments produced in relatively anoxic conditions during warm, wet periods. During the cool, dry periods, the relatively oxic water column limited increases in these metals in low-TC sediments. As a result, low TC and low acid-leached $\mathrm{Mn}, \mathrm{Sr}$ and $\mathrm{V}$ were associated with cool, dry periods. The reverse was true during warm, wet periods. Climate change clearly plays a major role in regulating distributions of metals in sediments, especially redox-sensitive ones.

Early diagenesis and changes in redox conditions can clearly affect distributions of certain elements in sediments of GGL. Nevertheless, well-preserved sediments still serve as a repository of aeolian flux of dust. Following the procedure of Chen et al. (2001), elements of aeolian flux near the tops of three cores are given in Table 3. A total of 35 elements are listed, including some unpublished data of Wann (2000). These include $\mathrm{Al}, \mathrm{As}, \mathrm{Ba}, \mathrm{Br}, \mathrm{Ca}, \mathrm{Cd}, \mathrm{Ce}$, $\mathrm{Cl}, \mathrm{Cr}, \mathrm{Cs}, \mathrm{Cu}, \mathrm{Er}, \mathrm{Eu}, \mathrm{Fe}, \mathrm{Ga}, \mathrm{Gd}, \mathrm{K}, \mathrm{La}, \mathrm{Lu}, \mathrm{Mg}, \mathrm{Mn}, \mathrm{Na}, \mathrm{Nd}, \mathrm{Ni}, \mathrm{Pb}, \mathrm{Rb}, \mathrm{Si}, \mathrm{Sm}, \mathrm{Sr}, \mathrm{Ti}, \mathrm{Tm}$, $\mathrm{V}, \mathrm{Yb}, \mathrm{Zn}$ and $\mathrm{Zr}$. Many of these elements were found in aerosols in Taiwan (Wang et al. 2004) and the fluxes compared reasonably well with direct flux measurements in and around Taiwan. Certain toxic elements, namely, $\mathrm{As}, \mathrm{Cd}, \mathrm{Cr}, \mathrm{Cu}, \mathrm{Ni}, \mathrm{Pb}$ and $\mathrm{Zn}$ were noted but micronutrients such as $\mathrm{Fe}$ and $\mathrm{V}$ serve to enhance biological productivity of aquatic environments. All four studies listed in Table 3 show rather large Fe flux indeed.

\section{CONCLUSIONS}

Variation in particle input with different organic matter content was the major factor regulating distributions of elements in sediments of GGL. Concentrations of $\mathrm{Al}, \mathrm{Cs}, \mathrm{Mg}, \mathrm{Rb}$ and $\mathrm{V}$, from mainly lithogenic (including aeolian) sources, were diluted by organic matter in sediments and were found to be low in mobile fractions. Organic matter was the major source of $\mathrm{C}$, $\mathrm{N}$ and $\mathrm{S}$, as well as As, and mainly occurred in oxidisable phases. This caused C, N, S and As to correlate well with TC in sediments. Most metals in mobile fractions were correlated well with TC, suggesting that organic matter plays a major role in remobilizing metals during early diagenesis. The annual Fe cycle in GGL also was also found to play a major role in regulating distributions of redox-sensitive elements (such as Fe, Mn and V) in sediments.

Climate-induced changes to the redox cycle in the water column might be partly responsible for distributions of elements and for positive correlations between TC and metals in mobile fractions. This was especially true for redox-sensitive elements. In addition to natural factors, anthropogenic activities affected distributions of metals in sediments through input of aeolian matter. Large amounts of anthropogenic $\mathrm{Cd}$ and $\mathrm{Pb}$ enriched surface sediments and occurred mainly in and/or transformed into exchangeable/carbonatic and easily reducible fractions, respectively. Finally, aeolian fluxes of micro-nutrients, such as Fe and V can serve to enhance biological productivity in aquatic environments. 

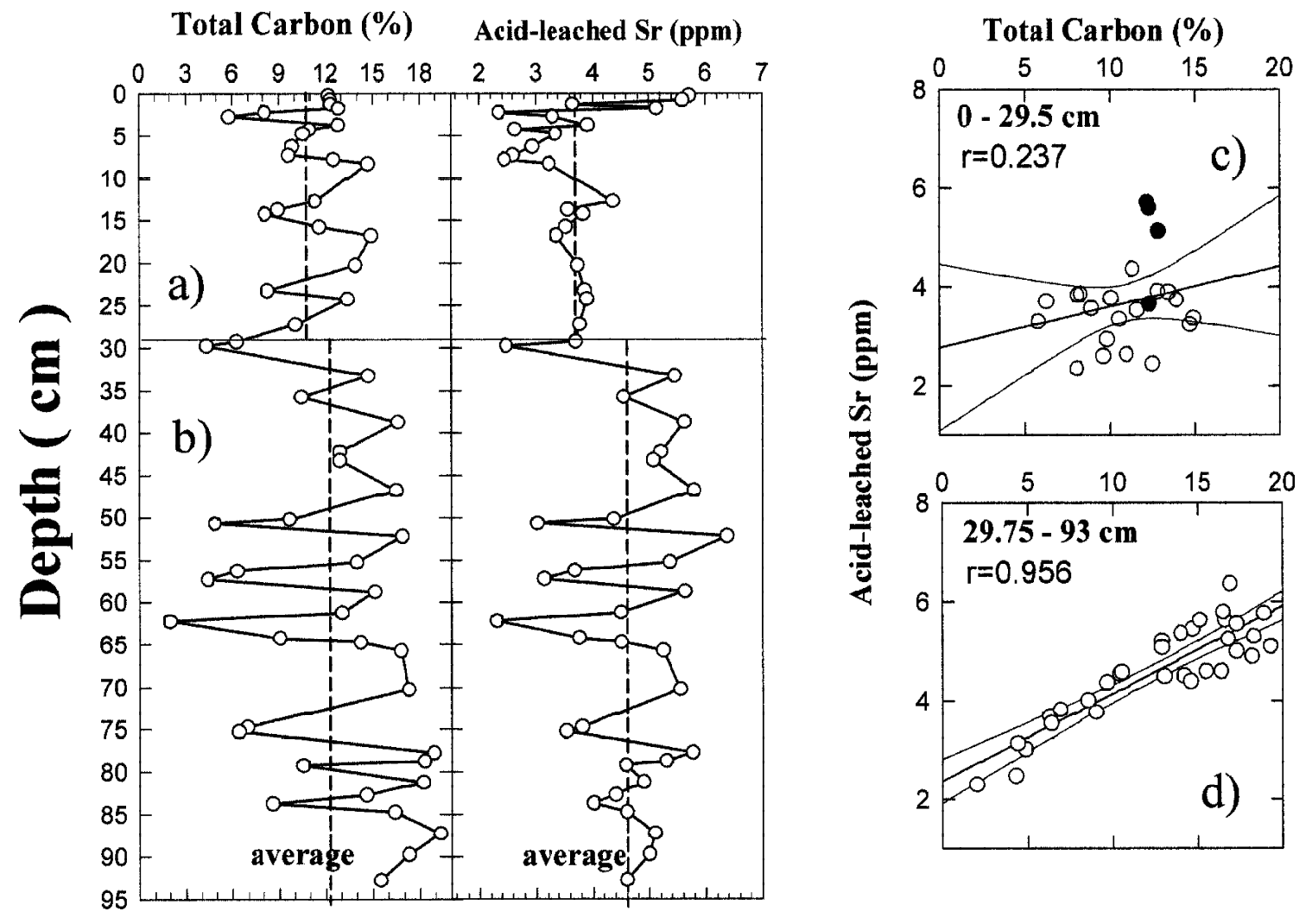

Fig. 11. Distribution of total carbon and acid-leached $\mathrm{Sr}$ in the sediments of GGL from (a) 0 to $30 \mathrm{~cm}$ and from (b) 30 to $93 \mathrm{~cm}$, as well as correlations between total carbon and acid-leached $\mathrm{Sr}$ from (c) 0 to $30 \mathrm{~cm}$ and from (d) 30 to $93 \mathrm{~cm}$. Dark circles represent those above $2 \mathrm{~cm}$; $r$ is 0.07 if these 4 points are excluded. The regression line and its $95 \%$ confidence range are marked.

Acknowledgements The authors wish to express their appreciation to the Environmental Protection Administration (EPA-86-FA44-09-26) and the National Science Council (NSC922611-M-110-014; 92-2611-Z-110-005) for supporting this research. Gratitude is also extended to Prof. Shiuh-Jen Jiang for assistance in the measurement of metals with the ICP-MS. Assistance in sampling, by colleagues at the laboratory, especially J. Y. Lou and M. H. Huang, is also appreciated. This paper was enhanced by the constructive remarks of D. E. Grandstaff and three anonymous reviewers. 
Table 3. Recent Aeolian Flux of Elements $\left(\mu \mathrm{g} \mathrm{cm}^{-2} \mathrm{yr}^{-1}\right)$ in and around Taiwan.

\begin{tabular}{|c|c|c|c|c|}
\hline Element & This Study ${ }^{a}$ & $\mathrm{Wu}(1996)$ & $\operatorname{Lin}(1996)^{b}$ & Hong et al. $(2002)^{\circ}$ \\
\hline $\mathrm{Al}$ & $188-194$ & $80.7-291$ & $0.72-480$ & 34.5 \\
\hline As & $0.016-0.019$ & $0.04-0.15$ & --- & 0.11 \\
\hline $\mathrm{Ba}$ & 0.451 & -- & --- & 0.36 \\
\hline $\mathrm{Br}$ & 0.027 & --- & --- & --- \\
\hline $\mathrm{Ca}$ & 0.763 & $\ldots$ & $\cdots$ & 43 \\
\hline $\mathrm{Cd}$ & $0.0006-0.0007$ & nd- 1.45 & $0.0001-0.040$ & 0.016 \\
\hline $\mathrm{Ce}$ & $0.195-0.214$ & --- & --- & 0.022 \\
\hline $\mathrm{Cl}$ & 0.722 & --- & --- & --- \\
\hline $\mathrm{Cr}$ & $0.145-0.151$ & $0.35-0.83$ & $0.0021-4.0$ & 1.13 \\
\hline $\mathrm{Cs}$ & $0.119-0.138$ & $\ldots$ & -. & $\ldots$ \\
\hline $\mathrm{Cu}$ & $0.098-0.106$ & $0.71-2.23$ & $0.0035-0.23$ & 0.089 \\
\hline Er & 0.006 & & & 0.00098 \\
\hline $\mathrm{Eu}$ & 0.0026 & & & 0.0011 \\
\hline $\mathrm{Fe}$ & $55.1-68.5$ & $52.4-182$ & $0.5-180$ & $51.5(17.2-154.4)^{\mathrm{d}}$ \\
\hline $\mathrm{Ga}$ & 0.019 & --- & --- & 0.041 \\
\hline $\mathrm{Gd}$ & 0.016 & & & 0.0019 \\
\hline $\mathrm{K}$ & 22.3 & --- & --- & 66 \\
\hline $\mathrm{La}$ & 3.63 & & & 0.012 \\
\hline $\mathrm{Lu}$ & 0.0009 & & & 0.00018 \\
\hline $\mathrm{Mg}$ & $10.8-12.3$ & $21-84.5$ & $4.1-143$ & 181 \\
\hline $\mathrm{Mn}$ & $0.375-0.478$ & $1.97-4.47$ & $0.01-2.39$ & 0.57 \\
\hline $\mathrm{Na}$ & 0.276 & --- & --- & 40 \\
\hline $\mathrm{Nd}$ & 0.061 & & & 0.0012 \\
\hline $\mathrm{Ni}$ & $0.059-0.069$ & $0.23-0.67$ & $0.013-1.23$ & 0.092 \\
\hline $\mathrm{Pb}$ & $0.124-0.176$ & $0.54-3.13$ & $0.0018-1.52$ & 0.6 \\
\hline $\mathrm{Rb}$ & $0.232-0.355$ & --- & --- & 0.056 \\
\hline $\mathrm{Si}$ & 246 & --- & --- & --- \\
\hline $\mathrm{Sm}$ & 0.013 & & & 0.0062 \\
\hline $\mathrm{Sr}$ & $0.129-0.151$ & $0.42-3.05$ & --- & 0.6 \\
\hline $\mathrm{Ti}$ & 3.56 & --- & --- & --- \\
\hline $\operatorname{Tm}$ & 0.0009 & & & 0.0002 \\
\hline $\mathrm{V}$ & $0.186-0.210$ & $0.22-0.75$ & --- & 0.049 \\
\hline $\mathrm{Yb}$ & 0.006 & & & 0.001 \\
\hline $\mathrm{Zn}$ & $0.236-0.261$ & $2.33-18.5$ & $0.03-3.24$ & 1.3 \\
\hline $\mathrm{Zr}$ & 0.194 & $\ldots$ & --- & 0.043 \\
\hline
\end{tabular}

a: data from the three cores, including the single core data published in Chen et al. (2001) and the unpublished data of Wann (2000).

b: calculated from his aerosol composition data using the particle settling speed of Milford and Davidson (1985).

c: flux of atmospheric elements over the East China Sea.

d: flux of atmospheric elements over the Yellow Sea (Hong et al. 1997). 


\section{REFERENCES}

Balistrieri, L. S., J. W. Murray, and B. Paul, 1992a: The cycling of iron and manganese in the water column of Lake Sammamish, Washington. Limnol. Oceanogr., 37, 510-528.

Balistrieri, L. S., J. W. Murray, and B. Paul, 1992b: The biogeochemical cycling of trace metals in the water column of Lake Sammamish, Washington: response to seasonally anoxic conditions. Limnol. Oceanogr., 37, 529-548.

Berner, R. A., 1981: A new geochemical classification of sedimentary environments. $J$. Sediment. Petrol., 51, 359-365.

Birch, L., K. W. Hanselmann, and R. Bachofen, 1996: Heavy metal conservation in Lake Cadagno sediments: historical records of anthropogenic emissions in a meromictic alpine lake. Water Res., 30, 679-687.

Carignan, R., and J. O. Nriagu, 1985: Trace metal deposition and mobility in the sediments of two lakes near Sudbury, Ontario. Geochim. Cosmochim. Acta, 49, 1753-1764.

Chen, C. T. A., and B. J. Wang, 1990: Winter overturning of the anoxic Great Ghost Lake. Proc. Nat. Sci. Coun., 14, 11-15.

Chen, C. T. A., J. Y. Luo, and J. K. Wann, 1993: Preliminary paleo- climatological records from high mountain lakes in Taiwan. TAO, 4, 321-330.

Chen, C. T. A., J. K. Wann, and J. Y. Luo, 2001: Aeolian flux of trace metals in Taiwan over the past 2600 years. Chemosphere, $\mathbf{4 3}, 287-294$.

Chiang, C. W., W. N. Chen, W. A. Liang, and J. B. Nee, 2004: Lidar measurements of spring dusts in 2002 at Chung-Li $\left(25^{\circ} \mathrm{N}, 121^{\circ} \mathrm{E}\right) . T A O, 15,813-824$.

Chou, C. C. K., C. Y. Lin, T. K. Chen, S. C. Hsu, S. C. Lung, S. C. Liu, and C. Y. Young, 2004: Influence of long-range transport dust particles on local air quality: A case study on the Asian dust episodes in Taipei during the spring of 2002.TAO, 15, 881-899.

Das, B. K., M. Singh, and R. Van Grieken, 1995: The elemental chemistry of sediments in the Nainital lake, Kumaun Himalaya, India. Sci. Total Environ., 168, 85-90.

Davison, W., 1985: Conceptual models for transport at a redox boundary. Chemical Processes in Lakes, Wiley, New York, 31-53 p.

Davison, W., and C. Woof, 1984: A study of the cycling of Mn and other elements in a seasonally anoxic lake, Rostherne Mere. U.K. Water Res., 18, 727-734.

Davison, W., C. Woof, and E. Rigg, 1982: The dynamics of iron and manganese in a seasonally anoxic lake: direct measurement of fluxes using sediment traps.Limnol. Oceanogr., 27, 987-1003.

Forstner, U., and G. T. W. Wittmann, 1983: Metal pollution in the aquatic environment. Springer-Verlag, Berlin, Heidelberg, New York, Tokyo, 133-136 p.

Francois, R., 1988: A study on the regulation of the concentrations of some trace metals $(\mathrm{Rb}$, $\mathrm{Sr}, \mathrm{Zn}, \mathrm{Pb}, \mathrm{Cu}, \mathrm{V}, \mathrm{Cr}, \mathrm{Ni}, \mathrm{Mn}$ and $\mathrm{Mo}$ ) in Saanich inlet sediments, British Columbia, Canada. Mar. Geol., 83, 285-308.

Giblin, A. E., G. E. Likens, D. White, and R. W. Howarth, 1990: Sulfur storage and alkalinity generation in New England lake sediments. Limnol. Oceanogr., 35, 852-869. 
Hamiltontaylor, J., W. Davison, and K. Morfett, 1996: The biogeochemical cycling of Zn, $\mathrm{Cu}, \mathrm{Fe}, \mathrm{Mn}$ and dissolved organic $\mathrm{C}$ in a seasonally anoxic lake.Limnol. Oceanogr., 41, 408-418.

Hong, G. H., J. Zhang, and C. S. Chung, (Eds.) 2002: Impact of Interface Exchange on the Biogeochemical Processes of the Yellow and East China Seas. Bumshin Press, Seoul, $519 \mathrm{p}$.

Hong, G. H., S. H. Kim, D. B. Yang, and G. H. Lim, 1997: Atmospheric input of trace metals over the Yellow Sea: Shipboard result. Proceedings of The Inter. Symp. on the Health of the Yellow Sea, April 1995, 91-119 p.

Huang, B. T., 1992: Stoichiometry of particulate organic carbon, hydrogen, oxygen, nitrogen and sulfur in lakes and reservoirs in Taiwan. Master Thesis, Nat. Sun Yat-Sen Univ., Taiwan, 82 p. (in Chinese)

Huang, B. T., and C. T. A. Chen, 1994: Stoichiometry of particulate organic carbon, hydrogen, oxygen, nitrogen and sulfur in lakes and reservoirs in Taiwan. Oceanologia et Limnologia Sinica, 25, 31-37 (in Chinese).

Hsu, S. C., S. C. Liu, C. Y. Lin, R. T. Hsu, Y. T. Huang, and Y. W. Chen, 2004: Metal compositions of $\mathrm{PM}_{10}$ and $\mathrm{PM}_{2.5}$ aerosols in Taipei during spring, 2002. TAO, 15, 925-948.

Kuivila, K. M., and J. W. Murray, 1984: Organic matter diagenesis in freshwater sediments: The alkalinity and total $\mathrm{CO} 2$ balance and methane production in the sediments of Lake Washington. Limnol. Oceanogr., 29, 1218-1230.

Lee H. C., and C. M. Liu, 2004: Coping with dust storm events: Information, impacts and policymaking in Taiwan. TAO, 15, 1035-1060.

Li,Y.H., 1981: Geochemical cycles of elements and human perturbation.Geochim. Cosmochim. Acta, 45, 2073-2084.

Lin, C. Y., S. C. Liu, C. C. K. Chou, T. H. Liu, C. T. Lee, C. S. Yuan, C. J. Shiu, and C. Y. Young, 2004: Long-range transport of Asian dust and air pollutants to Taiwan.TAO, 15, 759-784.

Lin, F. J., 1996: Composition and source characterization of marine atmospheric aerosols around Taiwan (II). Unpublished report, Nat. Sci. Coun. 85-2621-P-002A-001, Taipei.

Lin, Z. M., 1992: Preliminary study of sedimentary geochemistry in the Lung-Rung T'an and Hsiao-Kuei-Hu lakes. Master Thesis, Nat. Sun Yat-Sen Univ., Taiwan, 97 p.(in Chinese)

Liu, G. R., and T. H. Lin, 2004: Application of geostationary satellite observations for monitoring dust storms of Asia. TAO, 15, 825-837.

Lou, J. Y., C. T. A. Chen, and J. K. Wann, 1997: Paleoclimatological records of Great Ghost Lake in Taiwan. Sci. in China, 40, 284-292.

Martin, J. M., P. Nirel, and A. J. Thomas, 1987. Sequential extraction techniques: promises and problems. Mar. Chem., 22, 313-341.

Mester, Z., C. Cremisini, E. Ghiara, and R. Morabito, 1998: Comparison of two sequential extraction procedures for metal fractionation in sediment samples. Anal. Chim. Acta, 359, 133-142.

Milford, J. B., and C. I. Davidson, 1985: The sizes of particulate trace elements in the atmosphere-a review. APCA J., 35, 1249-1260. 
Ng, A., and C. C. Patterson, 1982: Changes of lead and barium with time in California offshore basin sediments. Geochim. Cosmochim. Acta, 46, 2307-2321.

NOAA, 1995: Standard and reference materials for environmental science. Silver Spring, Maryland, $751 \mathrm{p}$.

Nriagu, J. O., 1989: A global assessment of natural sources of atmospheric trace metals.Nature, 338, 47-49.

Patterson, C. C., and D. M. Settle, 1987: Review of data on eolian fluxes of industrial and natural lead to the lands and seas in remote regions on a global scale.Mar. Chem., 22, 137-162.

Premovic, P. I., N. Z. Pavlovic, M. S. Pavlovic, and N. D. Nikolic, 1993: Physicochemical conditions of sedimentation of the Fish Clay from Stevns Klint, Denmark, and its detrital nature: Vanadium and other supportive evidence. Geochim. Cosmochim. Acta, 57, 1433-1446.

Quevauviller, P. H., 1998: Operationally defined extraction procedures for soil and sediment analysis 1. Standardization. Trends. Anal. Chem., 17, 289-298.

Quevauviller, P. H., G. Rauret, J. F. Lopez-Sanchez, R. Rubio, A. Ure, and H. Muntau, 1997: Certification of trace metal extractable contents in a sediment reference material (CRM 601) following a three-step sequential extraction procedure. Sci. Total Environ., 205, 223-234.

Salomons, W., and U. Forstner, 1980: Trace metal analysis on polluted sediments. II. Evaluation of environmental impact. Environ. Technol. Lett., 1, 506-517.

Salomons, W., and U. Forstner, 1984: Metals in the hydrocycle. Springer-Verlag, Berlin, $85 \mathrm{p}$.

Schaller, T., H. C. Moor, and B. Wehrli, 1997: Reconstructing the iron cycle from the horizontal distribution of metals in the sediment of Baldeggersee. Aquatic Sci., 59, 326344.

Sigg, L., C. A. Johnson, and A. Kuhn, 1991: Redox conditions and alkalinity generation in a seasonally anoxic lake (Lake Greifen). Mar. Chem., 36, 9-26.

Stumm, W., and J. J. Morgan, 1981: Aquatic Chemistry, 2nd ed., Wiley-Interscience, New York, $583 \mathrm{p}$.

Surdam, R. C., S. W. Boese, and L. J. Crossey, 1984: The chemistry of secondary porosity. Am. Assoc. Pet. Geol. Mem., 127-149 p.

Templeton III, G. D., and N. D. Chasteen, 1980: Vanadium-fulvic acid chemistry: conformational and binding study by electron spin probe techniques. Geochim. Cosmochim. Acta, 44, 741-752.

Tessier, A., P. G. C. Campbell, and M. Bisson, 1979: Sequential extraction procedure for the speciation of particulate trace metals. Anal. Chem., 51, 844-851.

Tipping, E., 1981: The adsorption of aquatic humic substances by iron hydroxides. Geochim. Cosmochim. Acta, 45, 191-199.

Turekian, K. K., and K. H. Wedepohl, 1961: Distribution of the elements in some major units of the earth's crust. Bull. Geol. Soc. Am., 72, 175-192.

Wang, B. J., and C. T. A. Chen, 1990: Geochemistry of the anoxic Great Ghost Lake.Proc. Nat. Sci. Coun., 14, 16-20. 
Wang, C. C., C. T. Lee, S. C. Liu and J. P. Chen, 2004: Aerosol characterization at Taiwan's northern tip during ACE-ASIA. TAO, 15, 839-855.

Wann, J. K., 2000: Geochemistry and Paleoclimate of the Seasonally Anoxic Great Ghost Lake. Ph.D. Dissertation, Nat. Sun Yat-Sen Univ., 205 p.

Wann, J. K., C. T. A. Chen, Z. M. Lin, and S. J. Jiang, 1995: Sources and sinks of lead and other trace metals enriched in the surface sediments of remote subalpine lakes in Taiwan. $T A O, \mathbf{6}, 379-392$.

Wann, J. K., and C. T. A. Chen, 1996: Distribution of trace metals in the surface sediments of two pristine subalpine lakes in Taiwan. Chem. Ecol., 12, 67-89.

Wann, J. K., C. T. A. Chen, and B. J. Wang, 1997: A seasonally anoxic mountain lake with an active Fe cycle in tropical Taiwan. Aquatic Geochem., 3, 21-42.

Wilson, S. A., and J. H. Weber, 1979: An EPR study of the reduction of vanadium (V) to vanadium (IV) by fulvic acids. Chem. Geol., 26, 345-354.

Wu, Y. L., 1996: Investigation of total acid deposition and analysis of various mediums. Environment Protection Administration Report, Taipei, 52-55.

Xue, H. B., R. Gachter, and L. Sigg, 1997: Comparison of $\mathrm{Cu}$ and $\mathrm{Zn}$ cycling in eutrophic lakes with oxic and anoxic hypolimnion. Aquatic Sci., 59, 176-189.

Yuan, C. S., C. C. Sau, M. C. Chen, M. H. Huang, S. W. Chang, and Y. C. Lin, 2004: Mass concentration and size-resolved chemical composition of atmospheric aerosols sampled at Pescadores Islands during Asian dust storm periods in the years of 2001 and 2002. TAO, 15, 857-879. 